Southern Illinois University Carbondale

OpenSIUC

Publications

Department of Zoology

9-2009

\title{
Modeling Marine Protected Areas for Threatened Eiders in a Climatically Changing Bering Sea
}

James R. Lovvorn

Southern Illinois University Carbondale

Jacqueline M. Grebmeier

University of Maryland

Lee W. Cooper

University of Maryland

Joseph K. Bump

Samantha E. Richman

Southern Illinois University Carbondale

Follow this and additional works at: http://opensiuc.lib.siu.edu/zool_pubs

(C) 2009 by the Ecological Society of America

Published in Ecological Applications, Vol. 19, No. 6 (September 2009) at doi: 10.1890/08-1193.1

\section{Recommended Citation}

Lovvorn, James R., Grebmeier, Jacqueline M., Cooper, Lee W., Bump, Joseph K. and Richman, Samantha E. "Modeling Marine Protected Areas for Threatened Eiders in a Climatically Changing Bering Sea." (Sep 2009).

This Article is brought to you for free and open access by the Department of Zoology at OpenSIUC. It has been accepted for inclusion in Publications by an authorized administrator of OpenSIUC. For more information, please contact opensiuc@lib.siu.edu. 


\title{
Modeling marine protected areas for threatened eiders in a climatically changing Bering Sea
}

\author{
James R. Lovvorn, ${ }^{1,3}$ Jacqueline M. Grebmeier, ${ }^{2}$ Lee W. Cooper,${ }^{2}$ Joseph K. Bump, ${ }^{1,4}$ and Samantha E. Richman ${ }^{1}$ \\ ${ }^{1}$ Department of Zoology, University of Wyoming, Laramie, Wyoming 82071 USA \\ ${ }^{2}$ Chesapeake Biological Laboratory, University of Maryland Center for Environmental Science, Solomons, Maryland 20688 USA
}

\begin{abstract}
Delineating protected areas for sensitive species is a growing challenge as changing climate alters the geographic pattern of habitats as well as human responses to those shifts. When human impacts are expected within projected ranges of threatened species, there is often demand to demarcate the minimum habitat required to ensure the species' persistence. Because diminished or wide-ranging populations may not occupy all viable (and needed) habitat at once, one must identify thresholds of resources that will support the species even in unoccupied areas. Long-term data on the shifting mosaic of critical resources may indicate ranges of future variability. We addressed these issues for the Spectacled Eider (Somateria fischeri), a federally threatened species that winters in pack ice of the Bering Sea. Changing climate has decreased ice cover and severely reduced the eiders' benthic prey and has increased prospects for expansion of bottom trawling that may further affect prey communities. To assess long-term changes in habitats that will support eiders, we linked data on benthic prey, sea ice, and weather from 1970 to 2001 with a spatially explicit simulation model of eider energy balance that integrated field, laboratory, and remote-sensing studies. Areas estimated to have prey densities adequate for eiders in 1970-1974 did not include most areas that were viable 20 years later (1993-1994). Unless the entire area with adequate prey in 1993-1994 had been protected, the much reduced viable area in 1999-2001 might well have been excluded. During long non-foraging periods (as at night), eiders can save much energy by resting on ice vs. floating on water; thus, loss of ice cover in the future might substantially decrease the area in which prey densities are adequate to offset the eiders' energy needs. For wide-ranging benthivores such as eiders, our results emphasize that fixed protected areas based on current conditions can be too small or inflexible to subsume long-term shifts in habitat conditions. Better knowledge of patterns of natural disturbance experienced by prey communities, and appropriate allocation of human disturbance over seasons or years, may yield alternative strategies to large-scale closures that may be politically and economically problematic.
\end{abstract}

Key words: climate change; Endangered Species Act; energetics models; individual-based models; Macoma calcarea; marine reserves; Nuculana radiata; sea-ice effects on birds; Somateria fischeri; spatial foraging models; Spectacled Eider; trawling effects.

\section{INTRODUCTION}

As human impacts on natural habitats accelerate, there is increasing demand for defensible, quantitative delineations of protected areas for sensitive species (Murphy and Noon 1992, Pautzke 2005, Louzao et al. 2006). For wideranging predators in marine environments, suitable areas are often identified simply by describing the species' current dispersion (Boersma et al. 2002, Southall et al. 2006), and sometimes by characterizing used areas in terms of general physical attributes (Hooker et al. 1999,

Manuscript received 24 June 2008; revised 12 December 2008; accepted 7 January 2009. Corresponding Editor: J. M. Marzluff.

${ }^{3}$ Present address: Department of Zoology, Southern Illinois University, Carbondale, Illinois 62901 USA.

E-mail: lovvorn@zoology.siu.edu

${ }^{4}$ Present address: Michigan Technological University, School of Forest Resources and Environmental Science, Houghton, Michigan 49931-1295 USA.
Louzao et al. 2006). "Bioclimate envelopes," or the climatic niches of organisms (McMahon and Hays 2006), can effectively estimate overall range limits, but usually are not accurate enough at small scales to delineate protected areas in strongly contested locations (Pearson and Dawson 2003). Mapping prey availability can greatly refine the boundaries of suitable habitat (Stillman et al. 2005, Witt et al. 2007). However, even if thresholds of resources such as food can be identified by correlating animal distributions with resource levels, other important factors (e.g., dive depth, weather severity, distance from colonies) can alter these thresholds among areas (Rhodes et al. 2008). Moreover, diminished or wide-ranging populations often do not occupy all viable habitat at once, thereby confounding correlations between animal numbers and resource levels. In such cases, accurate determination of threshold food densities requires more comprehensive mechanistic models.

Even if numerical models of functional habitat dependencies are developed (Turner et al. 1994, Stillman 


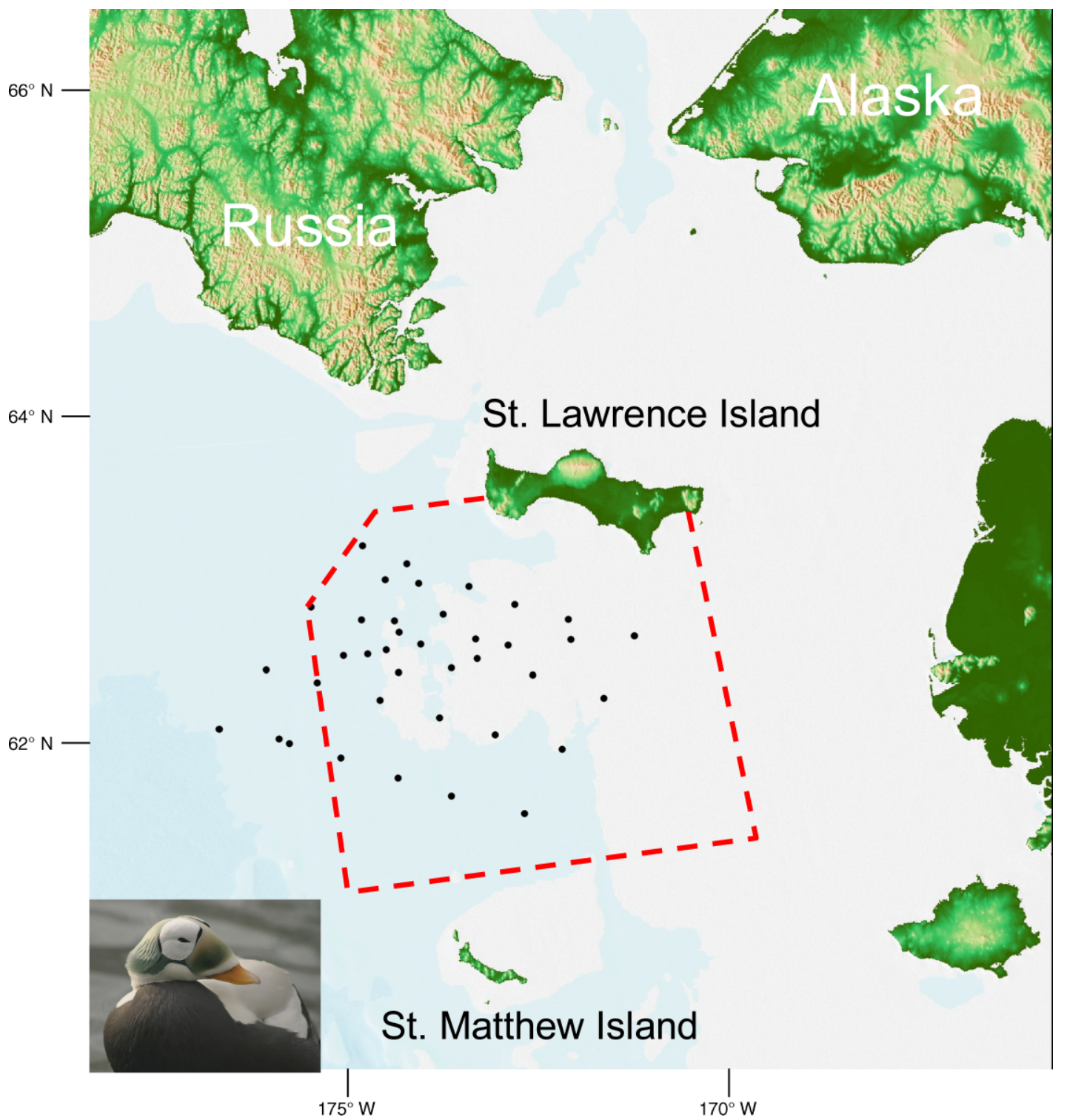

FIG. 1. Area in the north-central Bering Sea designated as critical habitat for Spectacled Eiders (Somateria fischeri) under the U.S. Endangered Species Act, delineated by the red dashed line. Current locations of benthic sampling stations are shown by solid circles. The inset photo of a Spectacled Eider is by Laura Whitehouse, U.S. Fish and Wildlife Service.

et al. 2005, Natori and Porter 2007), protected areas based on such models can be insufficient in the long term if the location or extent of viable habitat changes over time (Araújo et al. 2004, Hannah et al. 2007, Fuller et al. 2008). In marine systems, changing conditions can cause major regime shifts in abundance, dispersion, and structure of biotic communities over large areas at decadal or shorter timescales (Kröncke et al. 1998, Scheffer et al. 2001, Perry et al. 2005, Grebmeier et al. 2006). Areas that lack essential habitat elements now might become the only areas containing such elements in the future. Thus, in addition to including larger areas to buffer against periodic catastrophes (Allison et al. 2003), protected areas must account for projected habitat shifts due to climate change (Araújo et al. 2004, Hannah et al. 2007, Fuller et al. 2008).

Delineating protected areas is a key issue for Spectacled Eiders (Somateria fischeri). This species' world population winters in leads (openings in pack ice) in the Bering Sea (Fig. 1), where they dive 40-70 m for mostly bivalve prey (Lovvorn et al. 2003). The population of this species breeding in western Alaska declined by $96 \%$ from the early 1970 s to early 1990 s (Petersen et al. 2000), and Spectacled Eiders were declared threatened under the U.S. Endangered Species Act (ESA) in 1993. Causes of the major decline are unknown; at present, adult female mortality appears to limit the western Alaska population (U.S. Fish and 


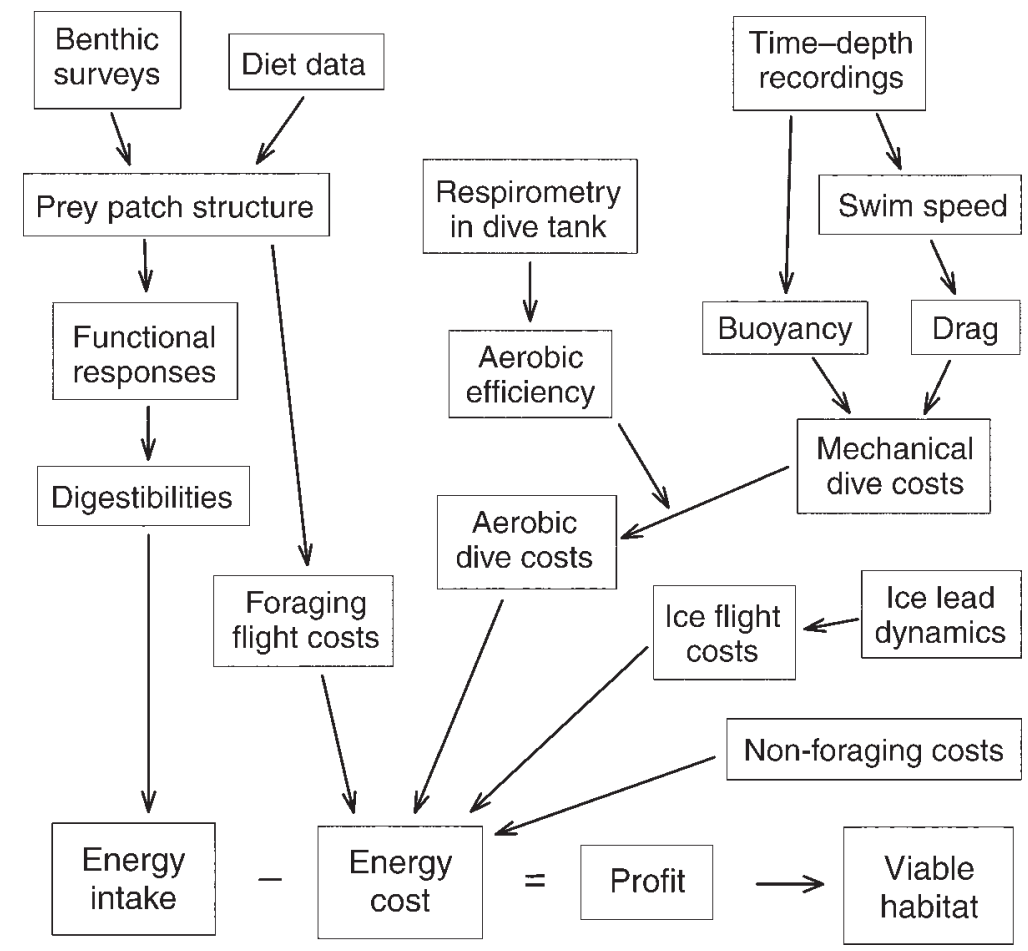

FIG. 2. Elements of the individual-based, spatially explicit simulation model of the energy balance of Spectacled Eiders during winter in the Bering Sea. Viable habitat occurs where energy intake balances or exceeds the costs during foraging bouts plus prorated costs incurred when the eiders are not foraging.

Wildlife Service 1996). Poisoning by ingestion of lead shotgun pellets causes important mortality on breeding areas, and may further compromise the eiders' tolerance of harsh conditions in early winter before overt residual effects of lead become negligible (5-7 weeks; Mautino and Bell 1986, 1987, Grand et al. 1998). Because up to $46 \%$ of annual mortality occurs during the nonbreeding period at sea (Flint et al. 2000), protection of adequate marine winter habitat is an important concern.

Regarding winter conditions, the major decline of this population encompassed a well-known shift to a warmer oceanic regime in the Bering Sea in 1976-1977, and perhaps another regime shift in 1989 (Hare and Mantua 2000). More recently, as bottom water temperatures have risen even more with climate warming, competing predators such as fish and crabs are moving farther north into the eiders' wintering region (Wyllie-Echeverria and Wooster 1998, Zheng et al. 2001, Conners et al. 2002, Grebmeier et al. 2006). As the distributions of commercially valuable fish shift northward, expansion of bottom trawling is also expected (Kruse 2007), with potentially important effects on benthic communities (McConnaughey et al. 2000, Barnes and Thomas 2005, Brown et al. 2005). Economic incentives to expand trawling may be high: Alaskan walleye pollock (Theragra chalcogramma) yield the largest landings of any fishery in the world, and Alaskan flatfish yield the largest flatfish landings in the world (Kruse 2007).
An important conservation and legal issue is that a large part of the area that may be opened to trawling is designated as critical habitat for Spectacled Eiders under the ESA (Fig. 1). However, within overall critical habitat, there may be sub-areas that lack the ESAsanctioned "primary constituent elements" essential to eiders. If the eiders' prospects for survival or recovery would not be affected, those nonessential sub-areas may be opened to bottom trawling. Thus, there is need to delineate accurately the sub-areas that can support eiders, and to consider how such areas might change over time. In particular, sea ice may be an important physical habitat component for eiders, and expected declines in sea ice (Overland and Wang 2007) may alter the adequacy of habitat defined by food resources. To address these issues, we integrated data on benthic prey in the eiders' wintering region over 31 years (1970-2001), and remote-sensing data and models for ice conditions under different weather regimes, into a simulation model of the energy balance of Spectacled Eiders.

\section{Methods \\ Overall model structure}

Our simulation model combined results from a range of field, laboratory, remote-sensing, and modeling studies (Fig. 2). Every dive, aerial flight, and period of non-foraging activity was simulated for individual eiders throughout the winter period. Energy intake rates 
depended on prey digestibilities; ingestion rates (functional responses) for different prey densities, sizes, and burial depths in sediments; and spatial patterns of those attributes interpolated from field samples at stations throughout the area (Fig. 1). Energy costs included immediate expense during foraging bouts, as well as prorated costs of all other activities when the birds were not foraging (including flights due to shifting ice conditions or to seek better feeding areas). The viability of a given location was determined by profitability (energy gain minus total costs) at that site (Fig. 2), and model birds sought better locations if profitability was negative. Mortality occurred when cumulative negative energy balance exceeded the stored energy reserves of the individual eider.

\section{Generating prey maps from benthic samples}

Field studies were conducted south of St. Lawrence Island in the north-central Bering Sea $\left(61.2-63.3^{\circ} \mathrm{N}\right.$, 170.0-175.3 ${ }^{\circ} \mathrm{W}$; Fig. 1). Water depth at sampling stations ranged from 30 to $100 \mathrm{~m}$. At each sampling station, 4-5 replicate benthic samples were collected with a custom-made van Veen grab (area of each sample $\sim 0.1 \mathrm{~m}^{2}$ ) and were washed over 1-mm (1993-2001, Grebmeier and Cooper 1995) or 3-mm (1970-1974, Stoker 1978) sieves. In 1993-1994 (25 stations) and 1999-2001 (37 stations), we measured shell lengths of bivalves to the nearest $0.1 \mathrm{~mm}$. In 1970-1974 (27 stations), we assumed that total numbers of the bivalve Macoma calcarea at each station (3-mm sieve) were $15.6 \%$ of lengths $12-18 \mathrm{~mm}, 5.9 \%$ of lengths $18-24 \mathrm{~mm}$, and $3.1 \%$ of lengths $24-30 \mathrm{~mm}$, based on mean percentages in different length classes for the overall area (Stoker 1978). These three length classes were used to generate prey maps because they were the main sizes in the bivalve diets of eiders studied in March 2001 (Lovvorn et al. 2003).

In March 2001, the diet of Spectacled Eiders consisted almost entirely of the most abundant bivalve (Nuculana radiata) of the most abundant size range, despite lesser availability of other species and sizes the eiders are known to eat elsewhere (Lovvorn et al. 2003). These data suggest that the eiders select the most common size range of the most abundant prey species, and that major shifts in prey dominance will result in rather complete shifts in diet. In the years of this study, either $M$. calcarea or $N$. radiata was overwhelmingly dominant, while the other species was far less common. Consequently, only the dominant prey species was used in simulations for each period.

For each station sampled in March-April 2001, numbers per square meter of $N$. radiata or $M$. calcarea in each of the three main length classes consumed by eiders were entered as separate layers into a Geographic Information System (ArcGIS, ESRI, Redlands, California, USA). We used inverse distance weighting to interpolate water depths and bivalve densities from values at the nearest five sampling stations. Resolution of the interpolated maps was set at $70 \mathrm{~m}$, corresponding to the estimated distance over the sea floor that a foraging eider would drift during a single dive cycle $(\sim 290 \mathrm{~s})$ at the average southward advection (winddriven) speed of the ice pack $(20 \mathrm{~km} / \mathrm{d}$ or $\sim 14 \mathrm{~m} / \mathrm{min}$; Niebauer et al. 1999; see Appendix for detailed explanation of prey map resolution).

\section{Energy costs of non-foraging surface behaviors}

In the model, the time when an eider was not diving or flying was allocated among resting on the ice or activities while floating on the water $(60 \%$ resting, $7 \%$ comfort movements, $1 \%$ social behaviors, $32 \%$ swimming; Systad et al. 2000). We applied these values to Spectacled Eiders during darkness when they were assumed not to feed (Systad et al. 2000, Lewis et al. 2005), as well as during non-foraging periods during daylight. Energy costs $(\mathrm{W} / \mathrm{kg}$ ) of non-swimming activities while floating on water were assumed to be the same as for a Common Eider (Somateria mollissima) floating in a respirometer at different water temperatures $T_{\mathrm{w}}\left(0-15^{\circ} \mathrm{C}\right)$ : $E_{\text {rest }}=5.48$ $-0.09 T_{\mathrm{w}}$; Jenssen et al. 1989). For surface swimming $\left(E_{\text {swim }}\right)$, we used $70 \%$ of the value of $12.2 \mathrm{~W} / \mathrm{kg}$ measured for Common Eiders swimming at $1 \mathrm{~m} / \mathrm{s}$ (Hawkins et al. 2000), to correspond to more efficient swimming at $\sim 0.5 \mathrm{~m} / \mathrm{s}$ (Prange and Schmidt-Nielsen 1970, Baudinette and Gill 1985). When Spectacled Eiders were out of the water and standing on ice, we used costs for Common Eiders at rest in air: $3.68 \mathrm{~W} / \mathrm{kg}$ at air temperatures $T_{\mathrm{a}}$ from $-2^{\circ}$ to $32^{\circ} \mathrm{C}$, and $E_{\text {ice }}=3.46$ $-0.07 T_{\mathrm{a}}$ for $T_{\mathrm{a}}$ below $-2^{\circ} \mathrm{C}$ (Jenssen et al. 1989). By these values, costs of surface-swimming and resting on water at $-1.7^{\circ} \mathrm{C}$ were about $50 \%$ higher than costs of resting on ice at the mean air temperature of $-14^{\circ} \mathrm{C}$ measured at the village of Savoonga on St. Lawrence Island, January-April, 2005-2006. Although advective heat loss due to wind might increase costs of resting on ice, effects of huddling in high-density flocks are expected to mitigate such increases (Gilbert et al. 2006).

\section{Power requirements of flight}

Flight speeds of a mix of eider species have been measured with radar as they migrated along the Beaufort Sea Coast (Day et al. 2004). Ground speed under various wind conditions averaged $84 \pm 11 \mathrm{~km} / \mathrm{h}$ (mean $\pm \mathrm{SD}$ ), ranging from 56 to $137 \mathrm{~km} / \mathrm{h}$. We used the mean speed of $84 \mathrm{~km} / \mathrm{h}$ to calculate the duration of flights of different distances.

The energy cost of aerial flight was calculated with Flight for Windows 1.14 (2004) software, an updated version of a model by Pennycuick (1989; available online). ${ }^{5}$ These simulations required body mass, wingspan, and wing area as input. Measurements of 12 adult female Spectacled Eiders collected in March 2001 (Lovvorn et al. 2003) yielded (means \pm SD) body mass

\footnotetext{
${ }^{5}\langle$ http://detritus.inhs.uiuc.edu/wes/pennycuick.html $\rangle$
} 
$1.550 \pm 0.120 \mathrm{~kg}$, wingspan $85.8 \pm 2.2 \mathrm{~cm}$, and wing area $1002 \pm 56 \mathrm{~cm}^{2}$ (including the section of the body between the wings; Pennycuick 1989). Based on these measurements, the curve of mechanical power $\left(P_{\text {mech }}\right)$ vs. airspeed yielded $33.3 \mathrm{~W}$ at $84 \mathrm{~km} / \mathrm{h}$.

We converted $P_{\text {mech }}$ into aerobic power ( $P_{\text {aerob }}$, power in terms of chemical substrates used) with an estimated aerobic efficiency $(\eta=$ mechanical power output $\div$ aerobic power input) of 0.23 (Pennycuick 1989), yielding $145 \mathrm{~W}$ or $93 \mathrm{~W} / \mathrm{kg}$. Based on the same algorithm and aerobic efficiency, calculated flight costs for Barnacle Geese (Branta leucopsis) were similar to respirometry measurements for that species during flight (see Bump and Lovvorn 2004).

\section{Weather, ice dynamics, and flight costs}

Aerial flight was required for the eiders to maintain geographic position over the sea floor as the ice pack was advected (moved) by prevailing winds. In the model, these repositioning flights to offset the mean ice-pack speed during the nighttime fast occurred in the morning before feeding began. Flight also occurred when foraging profitability at a given location was inadequate or when closing of leads forced the birds to seek open water. In such cases, eiders flew to the nearest lead, a distance estimated by Bump and Lovvorn (2004) for different weather-ice regimes. Shortest distance among leads and mean fetch across leads were measured at $12.5-\mathrm{m}$ pixel resolution with synthetic aperture radar data from satellites. We related these variables to prevailing wind speed, wind direction, and air temperature via correlation analyses, and estimated lead duration via models of lead freezing that depended on air temperature, wind speed, and fetch across leads (Bump and Lovvorn 2004).

Five weather-ice regimes were defined: Congelation, Frazil, Expansion, Consolidation, and Thaw. To summarize more detailed descriptions elsewhere (Bump and Lovvorn 2004), if air temperature was below freezing with little wind, leads froze over rapidly with sheet ice in the Congelation regime. At air temperatures below freezing, easterly or westerly winds created Frazil conditions, wherein ice crystals that form in near-surface waters accumulate at the downwind edge of a lead, from which ice formation advances in an upwind direction. Regardless of temperature, northerly winds moved ice floes southward, causing leads to propagate and diverge in the Expansion regime. Southerly winds had the opposite effect, forcing floes northward with convergence of leads in the Consolidation regime. If winds were calm and air temperature above freezing, leads were relatively stable or enlarged due to melting of ice in the Thaw regime.

For each weather-ice regime, we estimated the number and distance of flights caused by the closing of leads based on mean lead duration and the median distance to the nearest lead (Bump and Lovvorn 2004). For a mean flight speed of $84 \mathrm{~km} / \mathrm{h}$, total flight time per day owing to closing of leads was $31 \mathrm{~s}$ for Congelation, $20 \mathrm{~s}$ for Frazil, $1117 \mathrm{~s}$ for Consolidation, and zero for Expansion and Thaw. Thus, energy costs of flight forced by closing of leads ("lead close costs") were quite low for all regimes except Consolidation (which occurred infrequently, as did the Thaw regime).

To evaluate potential effects of severe ice conditions on lead close costs, we simulated the energy budgets of Spectacled Eiders for a winter in which the number of days between 15 December and 15 April in different weather-ice regimes was the average for the period 1950-2002, and for a winter (1967) when estimated flight distance due to closing of leads was the maximum during this period (Bump and Lovvorn 2004). Simulations were done for each day separately; however, if flight distance per day under each weather-ice regime is weighted by the percentage of days in that regime, we obtain a mean overwinter flight distance due to closing of leads of $4.80 \mathrm{~km} / \mathrm{d}$ for the multiyear average vs. 9.36 $\mathrm{km} / \mathrm{d}$ for the most severe year (1967).

\section{Prey dispersion and flight distance}

Because the ice pack moved southward with prevailing winds, the foraging location at the bottom for a given dive was on average about $70 \mathrm{~m}$ south of the location on the preceding dive (see Appendix). Thus, when foraging profitability in a particular area was below the needed threshold, only bird movements at a much larger scale were likely to result in appreciably different prey availability. Neither the direction nor distance of increased prey abundance was predictable or consistent throughout the prey field for a bird without prior knowledge. We initially assumed that eiders experiencing inadequate foraging profitability would fly to the nearest lead that was $\geq 5 \mathrm{~km}$ away. For all weather-ice regimes, there was always another lead within $5 \mathrm{~km}$, except for the Consolidation Regime, for which the median distance to nearest lead was $8.7 \mathrm{~km}$ (Bump and Lovvorn 2004) and flight distance was adjusted to that value. Single-parameter perturbations indicated that days of survival declined as foraging flight distance increased above $5 \mathrm{~km}$; however, we used a broad range of 5-20 km in uncertainty analyses. Choice of flight direction is described in the Methods section on Profitability and movement rules.

\section{Costs of descent and ascent during dives}

To estimate costs of diving, we used the modeling approach of Lovvorn et al. (2004). This approach estimates mechanical work against drag, buoyancy, and inertia during each swimming stroke at different depths, and then converts mechanical work into aerobic work (chemical substrate requirements) by means of an aerobic efficiency $\eta$ (Lovvorn 2007).

For free-ranging Spectacled Eiders wintering among leads in moving pack ice of variable thickness, capturing and recapturing the same individuals to deploy and recover time-depth recorders (TDRs) was not feasible. 
Consequently, swim speed and stroke patterns during descent and ascent were based on TDR and accelerometer data for free-ranging Thick-billed Murres (Uria lomvia) which were making vertical, direct dives to feed at a given depth (Lovvorn et al. 2004). By using parameters for Spectacled Eiders in a model that simulates mechanical work during each stroke at different depths (Lovvorn et al. 2004), and assuming that mean speeds and stroke patterns were the same as for Thick-billed Murres (Appendix), we calculated total mechanical work of descent ( $W_{\text {des }}$, in joules) for dives to a range of depths $(D)$. We then regressed $W_{\text {des }}$ on $D$ to yield $W_{\text {des }}=2.797+7.584 D\left(r^{2}=0.99, P<0.001\right)$ for dives to depths up to $75 \mathrm{~m}$. For the same range of depths, the total duration of descent $\left(T_{\text {des }}\right)$ was given by $T_{\text {des }}=0.818+0.783 D-0.0016 D^{2}\left(r^{2}>0.99, P<0.001\right)$. For total mechanical work during ascent $\left(W_{\text {asc }}\right)$, the regression was $W_{\text {asc }}=107.1-2.787 D+0.0350 D^{2}\left(r^{2}=\right.$ $0.98, P<0.001)$ for dives to depths of $35-75 \mathrm{~m}$ (encompassing the range of depths likely for eiders). The total duration of active strokes during ascent over the same depth range was given by $T_{\text {asc }}=-1.559+0.780 D$ $\left(r^{2}>0.99, P<0.001\right)$. Although there was negligible gliding between strokes during descent, there was substantial gliding between strokes during ascent (Lovvorn et al. 2004). The regression for the total duration of gliding during ascent was $T_{\text {glide }}=-10.859+$ $2.761 D-0.0130 D^{2}\left(r^{2}=0.98, P<0.001\right)$ for dives to depths of 35-75 m.

Regression estimates of $W_{\text {des }}$ and $W_{\text {asc }}$ were used to calculate total mechanical costs of descent and ascent during dives to the depths at different locations in the study area. Mechanical costs must be converted to aerobic costs by an aerobic efficiency $(\eta=$ mechanical power output $\div$ aerobic power input; Lovvorn 2007), for which no values have been determined for wingpropelled divers that also fly in air. We used the value of $\eta=0.14$ determined for foot-propelled Lesser Scaup (Aythya affinis) diving to a depth of $2 \mathrm{~m}$ in water at $8^{\circ} \mathrm{C}$ (Kaseloo and Lovvorn 2005). To estimate aerobic costs of gliding during ascent, we used an equation for the cost of resting on the water surface for Common Eiders (Jenssen et al. 1989), yielding $5.63 \mathrm{~W} / \mathrm{kg}$ at $-1.7^{\circ} \mathrm{C}$.

\section{Duration and cost of bottom foraging}

Time spent at the bottom during dives was based on TDR data from free-ranging Imperial Cormorants (Phalacrocorax atriceps) and Thick-billed Murres. Imperial Cormorants are mainly benthic feeders. Their body mass is highly variable but is $\sim 2.4 \mathrm{~kg}$ for males (Kato et al. 1992) and 15-19\% less for females (Brothers 1985). For these cormorants, time spent at the bottom increased with dive depth; over the depth range of 40-70 $\mathrm{m}$, the mean bottom time was $\sim 90 \mathrm{~s}$ (Kato et al. 1992, Wilson and Quintana 2004). For female Spectacled Eiders with mean mass of $1.55 \mathrm{~kg}$, we used the slope of the change in bottom time with depth for Imperial Cormorants (Wilson and Qintana 2004); however, we decreased the estimated bottom time in proportion to body mass by $15 \mathrm{~s}$ to account for effects of the lower mass of the eiders. The resulting equation was $T_{\text {bot }}=$ $10.85+1.19 D$, yielding bottom times $\left(T_{\text {bot }}\right)$ of $58-94 \mathrm{~s}$ over a range of dive depths $(D)$ from 40 to $70 \mathrm{~m}$. These values compare well to a mean bottom time of $\sim 65 \mathrm{~s}$ for Thick-billed Murres (body mass $\sim 1 \mathrm{~kg}$ ) feeding on benthic prey over the same depth range (Croll et al. 1992).

Mechanical work per stroke (by feet only) needed to stay at the bottom was calculated as the work needed to overcome buoyancy during a stroke period (1/stroke frequency; Lovvorn et al. 1991). For captive Spectacled Eiders, stroke rate of the feet during foraging at the bottom of a dive tank $2 \mathrm{~m}$ deep was $2.80 \mathrm{~Hz}$ (S. E. Richman and J. R. Lovvorn, unpublished data). Buoyancy at a given depth was estimated as described in the Appendix. The equation relating power required for stroking at the bottom $\left(P_{\text {str }}\right.$, in $\left.\mathrm{W}\right)$ to dive depth $(D$, in m) was $P_{\text {str }}=0.523-0.0331 D+7.84 \times 10^{-4} D^{2}-8.28$ $\times 10^{-6} D^{3}+3.318 \times 10^{-8} D^{4}\left(r^{2}=0.99, P<0.001\right)$. Aerobic efficiency $(\eta)$ at the bottom was assumed to be 0.14 , the same as for active stroking during descent and ascent.

\section{Maximum food loads, intake rates, and assimilation efficiencies}

Maximum food loads were determined from Spectacled Eiders collected in the study area in March 2001, and were adjusted for the relative dry mass and energy content of the bivalves $N$. radiata and $M$. calcarea (for details, see the Appendix). Functional responses (prey intake per unit time at different prey densities) were based on experiments with captive birds feeding on clams buried in trays of sediment at the bottom of a tank 2 m deep (Richman and Lovvorn 2003). Functional responses for different clam sizes and burial depths in sediments that were applied to $N$. radiata and $M$. calcarea are explained in the Appendix.

To account for different shell length classes in intake per dive, we first calculated the functional response for each shell length class assuming that all clams were of that shell length. We then multiplied those respective intake rates by the respective fractions (by number) of those length classes in the esophagi of collected eiders (10.2\% for $12-18 \mathrm{~mm}, 75.0 \%$ for $18-24 \mathrm{~mm}, 12.5 \%$ for 24-30 mm; Lovvorn et al. 2003) to obtain a weighted intake rate for each length class. The weighted intake rate for each length class was then multiplied by the bottom duration predicted for that depth to obtain the total intake of numbers of that length class during that dive. This weighting method is intended to account for variations in search and handling time (parameters in each functional response) for clams of different lengths consumed on a given dive.

Numbers of each length class consumed were converted to energy values, and then to energy assimilated based on assimilation efficiencies for energy of 0.673 for 
$N$. radiata and 0.759 for $M$. calcarea (measured by Richman and Lovvorn 2003). Energy assimilated from clams during the day that was used to meet energy requirements during non-foraging periods at night, and to fuel the morning flight to compensate for overnight southward drift, was converted to energy in body lipid until needed by a conversion efficiency of 0.6 (Lovvorn 1987).

As explained in the section on Generating prey maps from benthic samples, our simulations focused dichotomously on years when $M$. calcarea was dominant and $N$. radiata was essentially absent (1970-1974) vs. years when $N$. radiata was dominant and $M$. calcarea was far less common (1993-1994, 1999-2001). Thus, in a given simulation, we did not have to specify the relative fractions of different species that the eiders chose to exploit.

Prey availability at a given site was not decremented by the amount consumed by foraging eiders, because movement of the ice pack constantly shifted the area of bottom accessible to the eiders through a given lead. For example, for a lead $100 \mathrm{~m}$ wide moving southward at a mean speed of $20 \mathrm{~km} / \mathrm{d}$ (about $14 \mathrm{~m} / \mathrm{min}$ ), a square meter of bottom would be exposed to eider predation for only about $7 \mathrm{~min}$ as a lead passed over it.

\section{Profitability and movement rules}

Deciding when a cumulative energy deficit is sufficient to justify flying to a different area probably depends on learned expectations of what profitabilities might be at the same site vs. different sites (Bernstein et al. 1988). However, the time period and geographic area over which experience is integrated to yield such expectations are unknown. Consequently, we merely assumed that if cumulative energy balance after four consecutive dives was negative, the eiders flew to another location; uncertainty analyses (see Results) showed that wide variations in this assumed parameter had minimal effect on model outcomes. Conversely, if an eider filled its esophagus during a dive bout, it simply drifted southward with the ice pack for the digestion period required before feeding could resume (assumed to be 63 min, based on values cited in Guillemette [1994]).

After a decision to fly to a new area, the direction of flight depended on the change in profitability relative to that in the preceding bout. If the first bout of the day was unprofitable, the direction of flight was random. In later bouts in which profitability was negative but still the same or higher than in the preceding bout, the bird continued flying in the same direction as the preceding flight. In later bouts in which profitability was lower than in the preceding bout, the flight direction was altered depending on the amount of change in profit: the degrees of turning equaled the fraction of decrease in profit multiplied by $180^{\circ}$. For example, a $10 \%$ decrease in profit resulted in a turn of $0.1 \times 180^{\circ}=18^{\circ}$, whereas a decrease in profit of $90 \%$ resulted in a turn of $0.9 \times 180^{\circ}$ $=162^{\circ}$. The sense of the turn (to right or left) was randomly selected after the initial unprofitable bout, with the same sense retained in an unbroken series of unprofitable bouts. By this rule, the greater the decrease in profit after a foraging flight, the more likely the bird was to turn back toward a more profitable area.

This algorithm applied to sequential dives during a day as long as no profitable locations had been encountered. However, once any profitable location was encountered during a day, the model bird remembered the location of highest profit for that day. If the bird later drifted into an area with negative profit, it would fly back to the location where positive profit had been highest for the day, and would then drift southward between dives as long as profit remained positive.

\section{Diel foraging schedule and daily overhead cost}

To calculate foraging profitabilities required to maintain the needed energy balance, it is important to know what fraction of a $24-\mathrm{h}$ period the eiders forage, when enough energy must be gained to cover overhead costs during non-foraging periods. King Eiders (Somateria spectabilis) and Common Eiders, probably feeding mostly by vision on epifaunal prey such as mussels and urchins, are believed to feed only in daylight during winter at high latitudes (Systad et al. 2000; H. G. Gilchrist, personal communication). Because Spectacled Eiders in the Bering Sea feed by touch on infauna buried in soft sediments, and because there is negligible visible light at depths of $40-70 \mathrm{~m}$ during the day, light is not critical to search and handling per se. However, with leads that are sometimes $<100 \mathrm{~m}$ across moving at an average $14 \mathrm{~m} / \mathrm{min}$, and time underwater during individual dives being 3-4 min, relocating a lead during ascent may be problematic often enough to restrict foraging to daylight hours. As nighttime feeding has been rare or absent in other deeper-diving sea duck species elsewhere (Systad et al. 2000, Lewis et al. 2005), we assumed that Spectacled Eiders foraged only during daylight.

Time between sunrise and sunset for each day was taken from the U.S. Naval Observatory, Astronomical Applications (available online). ${ }^{6}$ By standard practice, we added one hour to account for extended illumination when the sun is below the horizon. Resulting daylight hours ranged from $6 \mathrm{~h}$ and $2 \mathrm{~min}$ at the winter solstice (21 December) to $15 \mathrm{~h}$ and $50 \mathrm{~min}$ on the last day of simulations (15 April). We then multiplied the number of hours of darkness by the cost of non-foraging surface activities. We assumed that during darkness the eiders drifted southward at the mean speed of the pack ice, 20 $\mathrm{km} / \mathrm{d}(14 \mathrm{~m} / \mathrm{min})$, and that at dawn they flew back to the location where they had been at the onset of darkness.

Energy costs of non-foraging surface activities at night, of dawn flights, and of flights due to closing of leads throughout a $24-\mathrm{h}$ period were added to yield a

\footnotetext{
${ }^{6}\langle$ http://aa.usno.navy.mil/data/docs/RS_OneYear.html $\rangle$
} 
TABLE 1. Parameters and their ranges used in uncertainty analyses of factors affecting days of survival (Table 2) and mean profit per dive (Table 3) of Spectacled Eiders (Somateria fischeri) in the Bering Sea.

\begin{tabular}{lcc}
\hline \hline \multicolumn{1}{c}{ Parameter } & Default & Range \\
\hline Multiple of mechanical cost of descent (W) & varies with depth & $\pm 20 \%$ \\
Aerobic efficiency for diving, $\eta$ & 0.14 & $0.10-0.25$ \\
Ratio of dive duration : pause duration & 2.4 & $\pm 20 \%$ \\
Multiple of bottom-foraging duration (s) & varies with depth & $\pm 15 \%$ \\
Ice pack speed (km/d) & 20 & $15-25$ \\
Number of unprofitable dives before flight movement & 4 & $3-6$ \\
Flight distance after unprofitable foraging (km) & 5 & $5-20$ \\
Flight speed (km/h) & 84 & $64-97$ \\
Multiple of lead close cost & varies with ice conditions & $\pm 20 \%$ \\
Non-foraging time spent resting on ice (\%) & 80 & $60-100$ \\
\hline
\end{tabular}

\footnotetext{
Notes: Ice regime was set for each day's simulation at one of the five weather-ice regimes, based on their mean probability of occurrence from 1950 to 2002. Prey density and water depth also varied depending on random starting locations and subsequent movements of eiders (Figs. 4 and

5). We calculated $\eta$ as mechanical power output $\div$ aerobic power input.
}

minimum overhead cost for a given day. This minimum overhead was prorated to each second of daylight and added to energy costs in calculations of foraging profitability (energy intake - cost) during daylight hours. When an eider located an area where its foraging profitability was positive (energy intake exceeded the cost of foraging plus the prorated overhead during foraging), it then had to accumulate enough additional profit to meet the cost of non-foraging surface activities in the remaining daylight hours before it could stop feeding for the day.

\section{Annual period for simulations}

For Spectacled Eiders instrumented with satellite transmitters, the median date of arrival on the wintering area from 1993 to 1996 was 17 October for four adult females captured on breeding areas that did not produce broods, and 7 November for nine adult females that produced broods (Petersen et al. 1999). In 1999, we observed that the last eiders remaining on the wintering area departed on 21 April, although it appeared that most of the population had left before our first aerial surveys on 13 April. For our analysis, we were interested in interactions between variations in the prey base and variations in ice conditions. Given that extensive ice cover typically forms in mid-December and lasts through mid-April, we ran model simulations for the period 15 December to 15 April.

\section{Criteria of habitat viability}

Because adult female mortality appears to be a major limiting factor for the western Alaska subpopulation of Spectacled Eiders (U.S. Fish and Wildlife Service 1996), our simulations focused on adult females. Initial body mass and energy reserves were estimated from eiders collected in the study area. Levels of reserve depletion at death by starvation were based on data from natural starvation events and laboratory studies (for details, see Appendix)

For each treatment in simulation experiments, 20000 eiders were started at random locations within each prey field. Two measures of viable habitat area were used. For an upper estimate of the fraction of the entire area that was suitable, a location was considered viable habitat if a model eider starting its movements from that location was able to survive winter (maintain net positive energy balance) even if profitability at the initial location was negative. A lower estimate of viable habitat areas was provided by determining the minimum prey density that allowed profitable foraging, and assessing the extent of areas above that threshold on the contour map of prey densities.

\section{Uncertainty analyses}

We evaluated effects of varying selected parameters (Table 1) on days of survival and mean profit per dive for the 1999-2001 prey field for $N$. radiata. In most cases we did not vary parameters by an arbitrary constant percentage, but rather over a range of values considered realistic for each parameter (Table 1; see Lovvorn and Gillingham 1996). All such parameters were considered uniformly distributed within the stated ranges. For parameters around which values were varied within percentages, default values were explained in preceding sections.

For uncertainty analyses, the value of each parameter for a given day was randomly chosen from the ranges listed in Table 1 and was held constant throughout that day. Ice regime was set for a day's simulation at one of the five weather-ice regimes, based on their mean probability of occurrence from 1950 to 2002. Parameters that changed with water depth or daily ice conditions were varied by multiples within the stated ranges. Based on the value of aerobic efficiency of $\eta=0.14$ determined for Lesser Scaup diving to $2 \mathrm{~m}$ in water at $8^{\circ} \mathrm{C}$ (Kaseloo and Lovvorn 2005), and higher values used for aerial flight (e.g., 0.23; Pennycuick 1989), we varied $\eta$ for diving between 0.10 and 0.25 . Ice pack speed was varied between published estimates of 15-25 km/d (Pease 1980, Niebauer et al. 1999). Flight speed was varied between 64 and $97 \mathrm{~km} / \mathrm{h}$, the range encompassing $95 \%$ of ground speeds measured by radar for a mix of eider species 

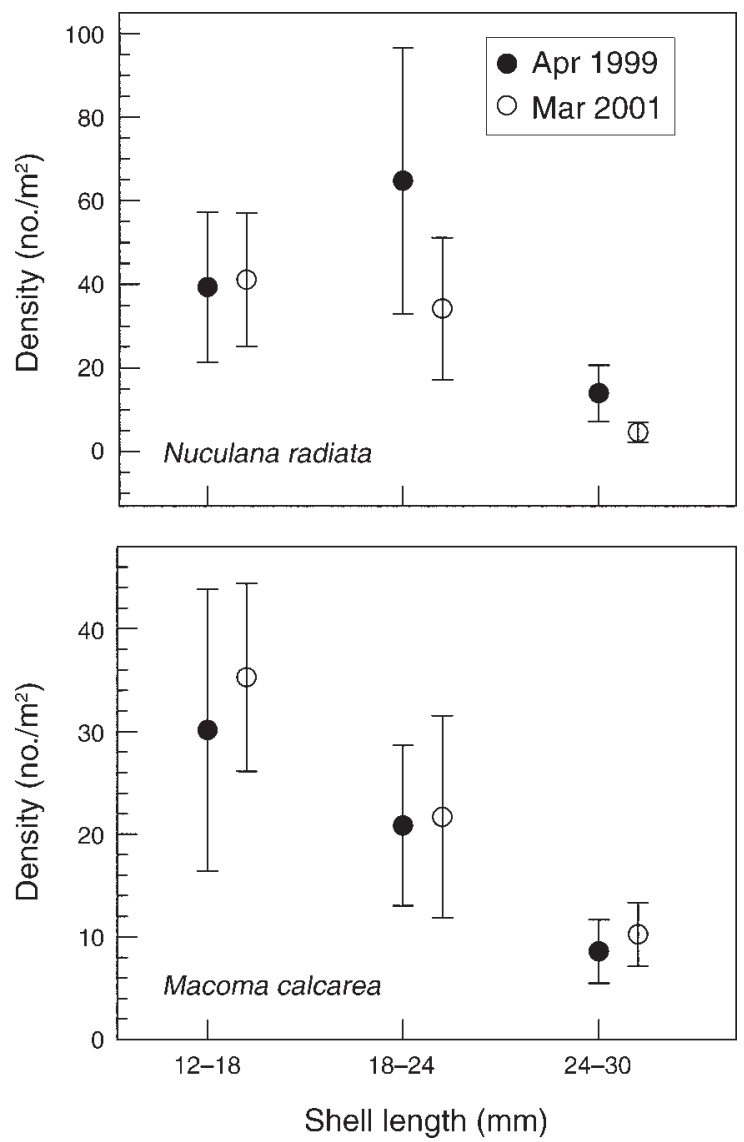

FIG. 3. Density (mean $\pm \mathrm{SE}$ ) of the bivalves Nuculana radiata and Macoma calcarea south of St. Lawrence Island in the Bering Sea in April 1999 and March 2001 ( $n=25$ stations that were sampled during both periods). Means did not differ between years for any length class of either species $(t$ tests paired by station: for $N$. radiata, all $P$ values were $0.07-0.97$; for $M$. calcarea, all $P$ values were $0.49-0.78$ ).

during migration (Day et al. 2004). These flight speeds corresponded to a range of energy costs from 134 to 161 $\mathrm{W}$. Non-foraging cost was varied to reflect a range of relative times spent sitting on the ice vs. resting, preening, and swimming on the water at representative air and water temperatures.

After simulations, all variables were ranked and the dependent variable (days of survival or mean profit per dive) was regressed against the independent variables (randomly chosen parameter values) for each day. Relative partial sums of squares (RPSS) for ranked data indicated the proportion of variance in days of survival or mean profit per dive explained by variation of individual parameters, with effects of the other varying parameters statistically removed (Lovvorn and Gillingham 1996). We also report partial coefficients of determination ( partial $r^{2}$ ), because parameters can show high correlation but account for small residual variances as indicated by RPSS. Together, these analyses indicate how much changes in the value of a parameter could affect the dependent variable (partial $r^{2}$ ), and where research effort to decrease the error in a parameter would improve the reliability of predictions (RPSS).

\section{Results}

\section{Patterns of bivalve density, 1970-2001}

Based on comparison of 25 stations that were sampled during both periods, bivalve densities for the survey area as a whole were very similar in April 1999 vs. March 2001 (Fig. 3). Because there were 37 stations sampled in March 2001 and only 26 stations in April 1999, we simulated spatial patterns in prey grids for 1999-2001 based on samples from March 2001. Although water depth (Fig. 4) varied enough to affect costs of diving by the eiders, attempts at co-kriging indicated that depth was not a useful predictor of density for any length class of either N. radiata or M. calcarea in March 2001. Other variables examined with co-kriging (mean grain size, organic carbon content, nitrogen content, and $\mathrm{C}: \mathrm{N}$ ratios of sediments) were also of no predictive value, and the assumption of stationarity (having the same spatial gradient at all locations throughout the area) was not met. Consequently, we interpolated the number of bivalves $/ \mathrm{m}^{2}$ for all periods from samples at different stations with inverse distance weighting (ESRI 2001).

Separate maps of prey occurrence were generated for 1970-1974 when Macoma calcarea was the dominant bivalve prey and the bivalve Nuculana radiata was rare (Stoker 1978), for 1993-1994 when N. radiata was the dominant bivalve prey and $M$. calcarea was far less common, and for 1999-2001 when $N$. radiata was still quite dominant but much less abundant than in 19931994 (Fig. 5). To increase the number of stations sampled for interpolation, prey maps for 1970-1974 and 1993-1994 included data from all years during those periods.

\section{Uncertainty analyses}

We evaluated the relative importance of variation in selected variables (Table 1) to days of survival by eiders (maintenance of positive energy balance including use of reserves of body fat and protein; see Appendix). We chose 20000 starting locations at random from the 1999-2001 prey field for N. radiata (Fig. 5); at 70-m resolution, this field contained $2789 \times 3857$ potential starting points. Model results indicated that most of the $59 \%$ of eiders that died did so within 20 to 30 days; otherwise, eiders survived the entire 122-day winter period. Regression of survival days on the selected variables (all values ranked before analysis) indicated their effect on whether a given starting location was in or near viable habitat that allowed overwinter survival. RPSS of $73 \%$ and partial $r^{2}$ of 0.70 showed that prey density was the overwhelming determinant of habitat viability (Table 2). Model estimates of survival days for random starting locations could be slightly improved by knowing (1) the percentage of time during non-foraging periods (as at night) that eiders spend sitting on ice vs. 


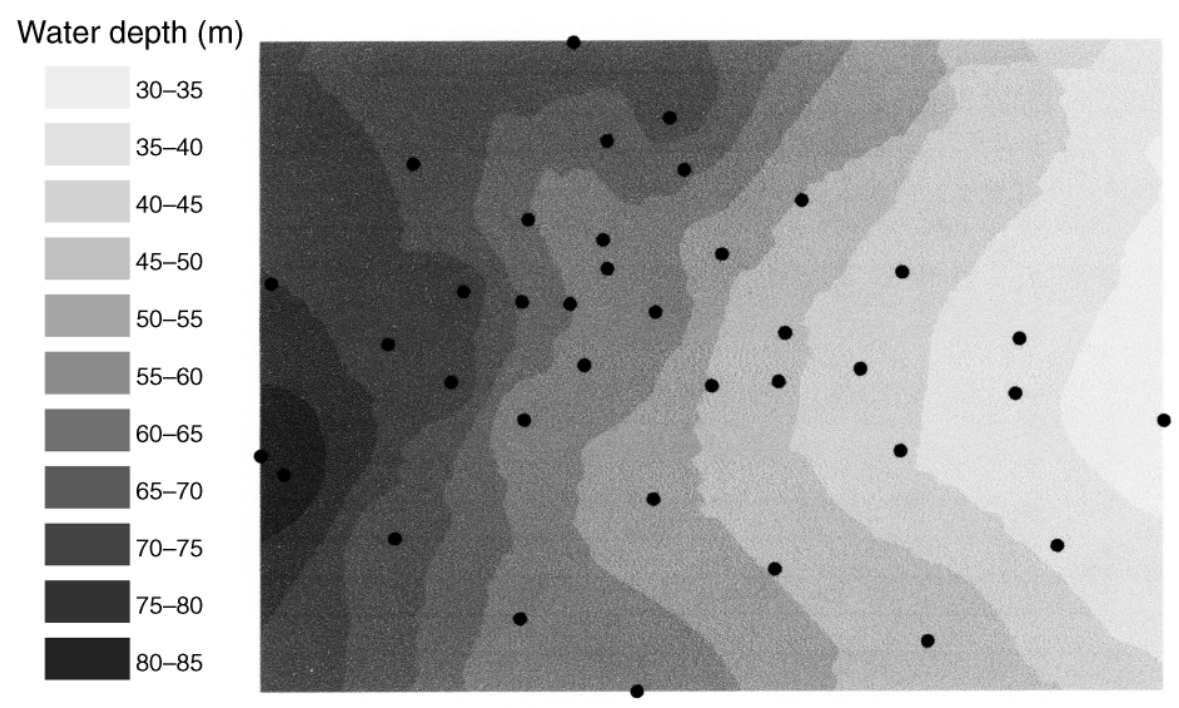

FIG. 4. Water depth throughout the study area, as interpolated by inverse distance weighting from depths at 37 sampling stations south of St. Lawrence Island (Fig. 1) in March 2001. Five neighborhood values (from the five nearest sampling stations) were used for interpolation. Mean prediction error was $-0.07 \mathrm{~m}$. Interpolated values saved for model simulations were on a uniform grid $196 \times 270 \mathrm{~km}$ with $70-\mathrm{m}$ resolution (see Appendix).

floating on water, (2) the distance flown to a new location after an unprofitable foraging bout, (3) the number of unprofitable dives before birds chose to move to another location, and (4) aerobic efficiency, which affects dive costs. For the first three variables we had no direct data; however, they had minimal effect on whether eiders survived winter when starting at random locations (partial $r^{2}=0.03-0.06$; Table 2).

Eiders are long-lived birds that probably remember general areas of viable habitat from year to year, or else can locate concentrations of other eiders in such areas. Consequently, we did additional uncertainty analyses only for eiders in viable habitat where they would likely be found. From the data set used to analyze effects of different variables on survival days (Table 2), we extracted data only for starting locations that allowed birds to survive winter, and regressed all variables on mean profit per dive (which subsumes overhead costs of other behaviors throughout the diel period). Once analyses were restricted to locations where prey density was adequate for survival, profit per dive was most affected by the duration of time spent foraging at the bottom during a dive ( $\mathrm{RPSS}=34 \%$, partial $r^{2}=0.27$; Table 3). The quality of viable habitat was still sensitive to prey density, but aerobic efficiency and the percentage of non-foraging time spent resting on ice actually had higher partial $r^{2}$ values for mean profit per dive. In contrast, variations in ice dynamics such as ice pack speed (affecting flight distance required to maintain geographic position) and the flight cost incurred by the closing of leads had negligible effects (Table 3 ). Number of dives before a movement decision and the distance flown after a decision to move were unimportant in areas where prey density was high enough to allow overwinter survival. Reasonable variation in the assumed speed and therefore cost of flight, or in mechanical costs of diving to which the aerobic efficiency was applied, also had little effect on model estimates of profit per dive (Table 3 ).

Results of uncertainty analyses suggest that further research to refine most default values in Table 1 is unjustified. However, measurements of time spent resting on the ice and foraging at the bottom, and of aerobic efficiency values in deep tanks, would improve model estimates of habitat viability.

\section{Effects of ice conditions}

Changing weather conditions might alter costs of flight to offset advection (forced movement) of pack ice by wind, or change how often or how far the eiders have to fly when leads they are in close due to freezing or convergence of the ice pack. Our simulations indicated that flights to maintain geographic position over the sea floor as the pack was advected southward were a relatively minor part of the eiders' energy budget (Fig. $6)$. Flight costs due to lead closure were high only when southward advection of the ice pack by prevailing northerly winds was opposed by a shift of winds to southerly; such conditions were relatively uncommon even in the most severe winter (1967). However, the eiders' estimated energy costs of floating on water are about $50 \%$ higher than the cost of resting on ice at ambient air and water temperatures; thus, availability of ice is very important during non-foraging periods, which account for a large fraction of the eiders' daily energy budget (Fig. 6). In fact, simulations using the prey grid for 1999-2001 (Fig. 5) indicate that if the percentage of non-foraging time spent resting on ice were decreased 


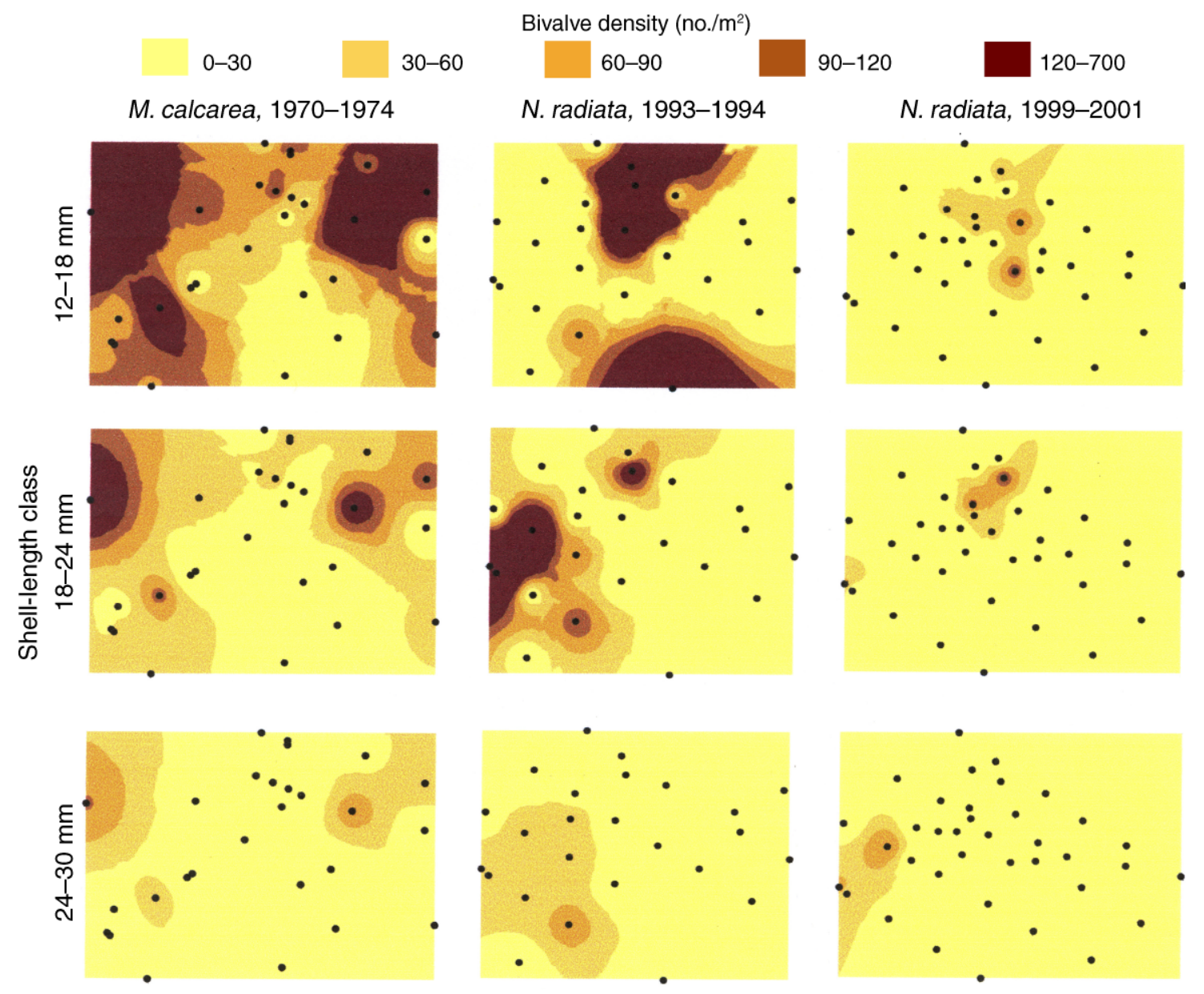

FIG. 5. Density of three shell-length classes of the bivalves Macoma calcarea and Nuculana radiata in 1970-1974, 1993-1994, and 1999-2001 during strong dominance by the species shown, interpolated from samples at the indicated stations. Shell-length classes comprised 10\% (12-18 mm), 75\% (18-24 mm), and 13\% (24-30 mm) dry mass of the diet of eiders in March 2001 (Lovvorn et al. 2003). Map dimensions were $\sim 192 \times 271 \mathrm{~km}$ in both $1970-1974$ and $1999-2001$, and $270 \times 220 \mathrm{~km}$ in $1993-1994$. In simulations, eiders could forage profitably in areas where densities of the three length classes combined were $>90 / \mathrm{m}^{2}(\mathrm{see}$ Fig. 8 ).

from $80 \%$ to $0 \%$, the percentage of the overall area that was viable habitat would decrease from $40 \%$ to $0 \%$ (based on viable starting locations, Fig. 7).

\section{Long-term changes in profit per dive}

Prey density was by far the most important variable affecting days of survival and the fraction of the study area that was viable habitat (Table 2). Simulated profit per dive averaged over the year for different individuals generally became negative as mean clam density declined below 90 clams $/ \mathrm{m}^{2}$ (Fig. 8). In simulations, prey availability during both $M$. calcarea dominance in the early 1970 s and $N$. radiata dominance in the early 1990 s was adequate to prevent appreciable eider mortality from starvation (survival at $>97 \%$ of random starting locations; mean profit/dive often high and usually $>0$; Fig. 8). However, as abundance of $N$. radiata declined from the early 1990 s to early 2000 s without compensatory increase of $M$. calcarea, the area of viable habitat for eiders decreased substantially (survival at only $40 \%$ of starting locations; mean profit/dive small and often $<0$; Fig. 8).

Sub-areas delineated as viable habitat $\left(>90\right.$ clams $\left./ \mathrm{m}^{2}\right)$ based on prey conditions in the early 1970s would not have included most of the viable sub-areas in either 1993-1994 or 1999-2001 (Fig. 5). If critical sub-areas had been delineated based on prey conditions in 19931994, the much smaller viable sub-areas remaining in 1999-2001 might have been excluded unless the entire viable area in 1993-1994 had been protected.

\section{DISCUSSION}

Pressing conflicts between humans and the needs of sensitive species often create demand to delineate protected areas with fixed boundaries based on current conditions (Murphy and Noon 1992, Hooker et al. 1999, Murawski et al. 2000). Our study shows that for marine endotherms that range over large areas seeking high densities of benthic prey, large-scale shifts in the habitat mosaic can render fixed protected areas mostly ineffec- 
TABLE 2. Relative partial sums of squares (RPSS) and partial coefficients of determination (partial $r^{2}$ ) for uncertainty analyses of the model for Spectacled Eiders, with dependent variable $=$ number of days of survival.

\begin{tabular}{lrr}
\hline \hline \multicolumn{1}{c}{ Parameter } & $\begin{array}{c}\text { RPSS } \\
(\%)\end{array}$ & $\begin{array}{r}\text { Partial } \\
r^{2}\end{array}$ \\
\hline Prey density & 73.42 & 0.70 \\
Non-foraging time spent resting on ice (\%) & 9.81 & 0.06 \\
Flight distance after unprofitable foraging & 7.18 & 0.05 \\
No. unprofitable dives before flight movement & 3.80 & 0.03 \\
Aerobic efficiency for diving, $\eta$ & 3.07 & 0.02 \\
Multiple of bottom-foraging duration & 0.95 & 0.01 \\
Ratio of dive duration to pause duration & 0.57 & $<0.01$ \\
Ice pack speed & 0.57 & $<0.01$ \\
Multiple of mechanical cost of descent & 0.47 & $<0.01$ \\
Water depth & 0.25 & $<0.01$ \\
Flight speed (power) & 0.13 & $<0.01$ \\
Multiple of lead close cost & 0.04 & $<0.01$
\end{tabular}

Notes: Number of days of survival was simulated for each of 20000 individuals whose starting locations were randomly selected from the prey grid for the bivalve Nuculana radiata in 1999-2001 (see Fig. 5). For each day, a constant value for each parameter was randomly chosen from ranges in Table 1. Flight power was a direct function of flight speed. RPSS values indicate the percentage of variance in survival days explained by variation in each parameter, with effects of the other parameters statistically removed. Multiple $R^{2}=0.89(P<0.01)$.

tive at timescales from only a few years to decades (Fig. 5). Although this problem has been recognized for pelagic predators whose water-column prey shift with variable oceanographic patterns (Boersma et al. 2002, Louzao et al. 2006, Southall et al. 2006), we have shown that prey dispersion for benthic predators can also change dramatically. Moreover, our model indicates for the first time how much the availability of pack ice might affect the energy balance of eiders, thereby altering the extent of areas with prey densities high enough to meet their energy needs. Thus, one must consider not only long-term shifts in the habitat mosaic of prey, but also climatic trends in extent and duration of ice cover. Such variations highlight the challenge of delineating fixed boundaries for marine reserves or critical habitat under the ESA, when such boundaries must be rigorously defensible in the short term, and are often difficult to alter once they are designated.

\section{Effects of ice conditions}

Our model indicates that costs of flight due to closing of leads or to maintain geographic position in moving pack ice had relatively small effects on the annual energy balance of eiders. However, because the model eiders spent so much time in non-foraging behaviors (including the nighttime fast), the much lower cost of resting on ice vs. floating on water during non-foraging periods had great effect on overall energy balance and the extent of viable habitat. By estimates used in the model, resting and swimming on the water surface cost eiders about 1.3 and 1.9 times more, respectively, than resting on ice at typical water $\left(-1.7^{\circ} \mathrm{C}\right)$ and air $\left(-14^{\circ} \mathrm{C}\right)$ temperatures. For Black-legged Kittiwakes (Rissa tridactyla), resting on water cost at least $40 \%$ more than resting in air, even at the much warmer temperature of $12.5^{\circ} \mathrm{C}$ (Humphreys et al. 2007). As temperature decreased from $23^{\circ}$ to $8^{\circ} \mathrm{C}$, the cost of resting on water increased by $58 \%$ for Lesser Scaup ducks and by $64 \%$ for Mallards (Anas platyrhynchos) (Kaseloo and Lovvorn 2003, 2005). Thus, our assumption that floating on water cost about 1.5 times more than resting on ice at ambient temperatures seems reasonable.

The lower cost of resting on ice might be increased by advective heat loss in high winds. However, the eiders' habit of clustering in large, dense flocks probably mitigates this effect, and may further reduce thermoregulation costs by substantially increasing ambient temperature within huddled groups (Gilbert et al. 2006). Under severe winter conditions, Common Eiders roosting on ice jostled constantly to achieve and maintain positions within the interior of dense clusters of birds (H. G. Gilchrist, unpublished data).

There is widespread concern that loss of sea ice could have grave consequences for walruses, which need ice for hauling out (Cooper et al. 2006), and for polar bears (Ursus maritimus), which use ice as a platform for hunting ice-dependent seals (Stirling and Parkinson 2006). Likewise, our model predicts that Spectacled Eiders could not persist in this area in years of low prey availability such as 1999-2001 (Fig. 5) if there were no pack ice for resting during non-foraging periods. As the percentage of non-foraging time spent resting on ice decreased from $80 \%$ to $20 \%$, nighttime energy cost (a large fraction of daily expenditure) increased by almost $40 \%$ and the percentage of viable habitat decreased to almost zero, with no change in food availability (Fig. 7). Aerial surveys indicated that a large fraction of eiders was often resting on ice during the day (Bump and Lovvorn 2004). However, we have no data on the percentage of time that Spectacled Eiders spend on the

TABLE 3. Results of uncertainty analyses of the model for Spectacled Eiders, with dependent vraiable $=$ mean profit per dive.

\begin{tabular}{lrr}
\hline \hline \multicolumn{1}{c}{ Parameter } & RPSS & Partial \\
& \multicolumn{1}{c}{$(\%)$} & $r^{2}$ \\
\hline Multiple of bottom-foraging duration & 33.95 & 0.27 \\
Prey density & 24.21 & 0.12 \\
Aerobic efficiency for diving, $\eta$ & 16.49 & 0.16 \\
Non-foraging time spent resting on ice (\%) & 14.34 & 0.17 \\
Ratio of dive duration to pause duration & 6.14 & 0.08 \\
Multiple of mechanical cost of descent & 2.82 & 0.04 \\
Ice pack speed & 1.29 & 0.02 \\
Flight distance after unprofitable foraging & 0.34 & $<0.01$ \\
Flight speed (power) & 0.22 & $<0.01$ \\
No. unprofitable dives before flight movement & 0.13 & $<0.01$ \\
Multiple of lead close cost & 0.04 & $<0.01$ \\
Water depth & 0.03 & $<0.01$ \\
\end{tabular}

Notes: For the 8094 individuals from simulations for Table 2 whose starting locations allowed them to survive winter, mean profit per dive was calculated for the winter period. Other conventions are as in Table 2. Here RPSS values indicate the percentage of variance in mean profit per dive explained by variation in each parameter, with effects of the other parameters statistically removed. Multiple $R^{2}=0.86(P<0.01)$. 


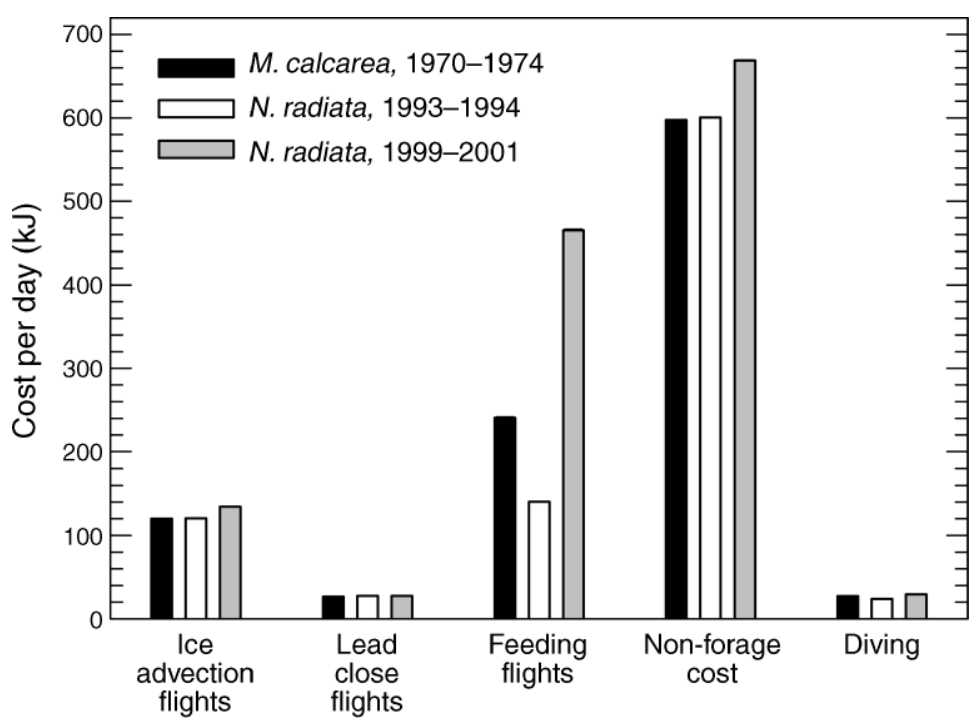

FIG. 6. Model estimates of energy costs per day due to (1) flights to offset advection (wind-driven movement) of the ice pack during nighttime fasting; (2) flights forced by closing of leads; (3) flights to seek better feeding areas and to offset daytime advection of ice; (4) non-foraging activities (excluding flight), assuming that $80 \%$ of non-foraging time was spent resting on ice (cf. Fig. 7); and (5) diving, based on prey grids for Macoma calcarea in 1970-1974, Nuculana radiata in 1993-1994, and N. radiata in 1999-2001 (Fig. 5). Ice conditions were selected daily in proportion to their mean annual occurrence in 1950-2002. Standard errors are too small to be seen.

ice during non-foraging periods, or how that percentage varies with weather and ice conditions. Indeed, ice extent in this region for most of winter 2001 was the lowest on record, with the area south of St. Lawrence Island being mostly free of ice until March (Clement et al. 2004). We found eiders there after pack ice formed in late March 2001, but do not know where they were earlier in winter.

Severe decreases in Bering Sea ice extent in the early 2000 s occurred well after the major decline in the Spectacled Eider population that breeds in western Alaska. Thus, despite less dramatic reductions in ice extent between the late 1970s and early 1990s (Niebauer et al. 1999), it is unlikely that availability of ice for roosting was important in Spectacled Eider declines during that period (see also Petersen and Douglas 2004). Nevertheless, our model suggests the importance of the presence of sea ice to predicting the future trajectory of climate effects on Spectacled Eiders.

\section{Effects of dive costs}

Under all conditions of prey availability examined here, costs of diving were a relatively minor component of the energy budget of eiders (Fig. 6). The limited role of dive costs might seem surprising for birds diving to depths of $40-70 \mathrm{~m}$ in water at $-1.7^{\circ} \mathrm{C}$. However, the model indicates that a relatively small fraction of the day was spent diving, and a variety of biomechanical and physiological adaptations allows birds such as eiders to minimize the cost of deep dives (Lovvorn et al. 2004, Heath et al. 2006, Lovvorn 2007, Richman and Lovvorn 2008; see Appendix).
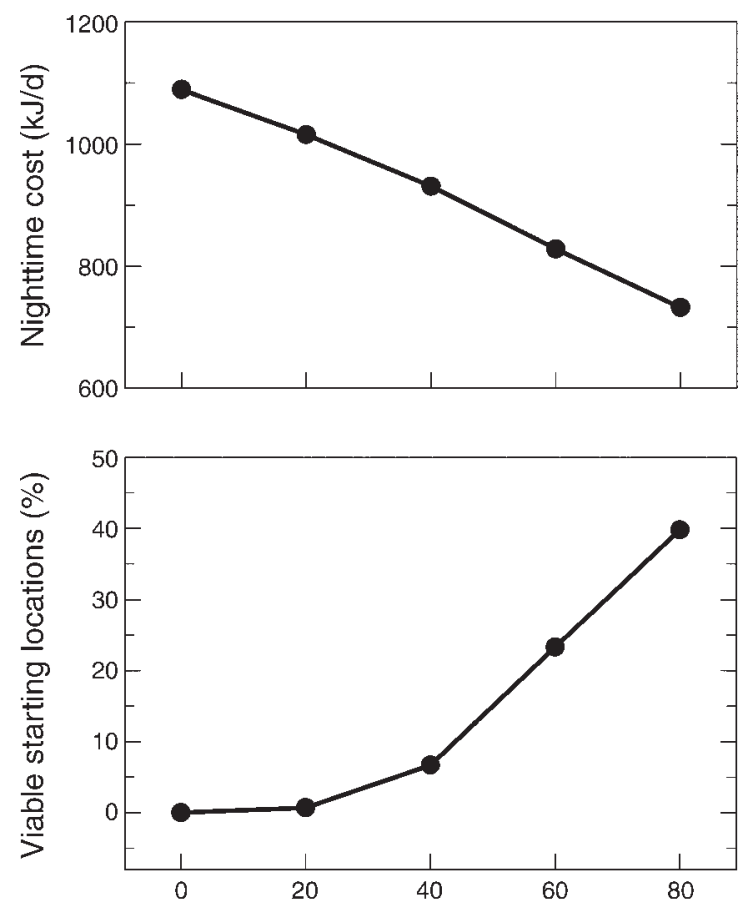

Non-foraging time spent resting on ice (\%)

FIG. 7. Simulated effects of the percentage of non-foraging time spent resting on the ice on activity costs during the nighttime fast, and on the percentage of random starting locations from which eiders survived winter $(n=20000$, for the $N$. radiata grid in 1999-2001). Standard errors are smaller than plotted symbols. 
In uncertainty analyses, variations in mechanical costs of diving had little effect on mean profit per dive in areas where prey density was adequate for survival (Table 3). However, variations in the aerobic efficiency (mechanical power output $\div$ aerobic power input) applied to mechanical models to estimate food requirements had appreciable effects on profit per dive (Table 3). Aerobic efficiencies, which subsume costs of thermoregulation, are poorly known and might be quite low in cold water. However, in large, well-insulated birds such as eiders, heat produced by exercising muscles may replace much of the heat lost to water (Lovvorn 2007). The eiders' use of both wings and feet for propulsion during descent can reduce costs by $34 \%$ over foot propulsion alone, probably due to greater efficiencies of both propulsion and thermoregulation (Heath et al. 2006, Richman and Lovvorn 2008). Measurements of aerobic efficiency for eiders in cold water in deeper tanks would provide more confidence in model estimates.

\section{Effects of conspecific attraction and prey depletion}

For species that typically aggregate in large flocks, such as Spectacled Eiders in winter, attraction to conspecifics is undoubtedly an important aspect of habitat selection (Amano et al. 2006). We addressed this issue partly by restricting some analyses to locations where eiders were modeled to survive winter (Table 3), assuming that individuals could easily locate large flocks that concentrate in viable habitat. Our purpose here was not to test predictions of the dispersion of birds according to their search strategies, because we lacked comprehensive data on the dispersion and sizes of flocks over winter. Rather, our intent was to estimate the fraction of the overall region in which eiders could survive regardless of how they located those areas, and to identify factors affecting the viability of those locations. The benefits of conspecific attraction are often linked to rates of prey depletion (Beauchamp et al. 1997, Amano et al. 2006), a factor that we also did not consider. Our once-per-season icebreaker cruises into this otherwise inaccessible area did not allow monitoring of progressive prey depletion over winter. Moreover, rate of prey depletion and the eiders' response to it depend strongly on rates of consumption of the same prey by other abundant predators, including fish, crabs, gastropods, and sea stars. Studies of the densities, diets, and consumption rates of these competing predators over the same sampling grid are ongoing, and should provide better estimates of prey depletion over time.

\section{Climate and eider declines}

The population of Spectacled Eiders nesting in western Alaska declined by $96 \%$ between the early 1970s and early 1990s. Our simulations indicate that food was not limiting to eiders during winter in 19701974 or 1993-1994. However, the major shift in dominant prey species between these two periods, and large decline of $N$. radiata in only five years between

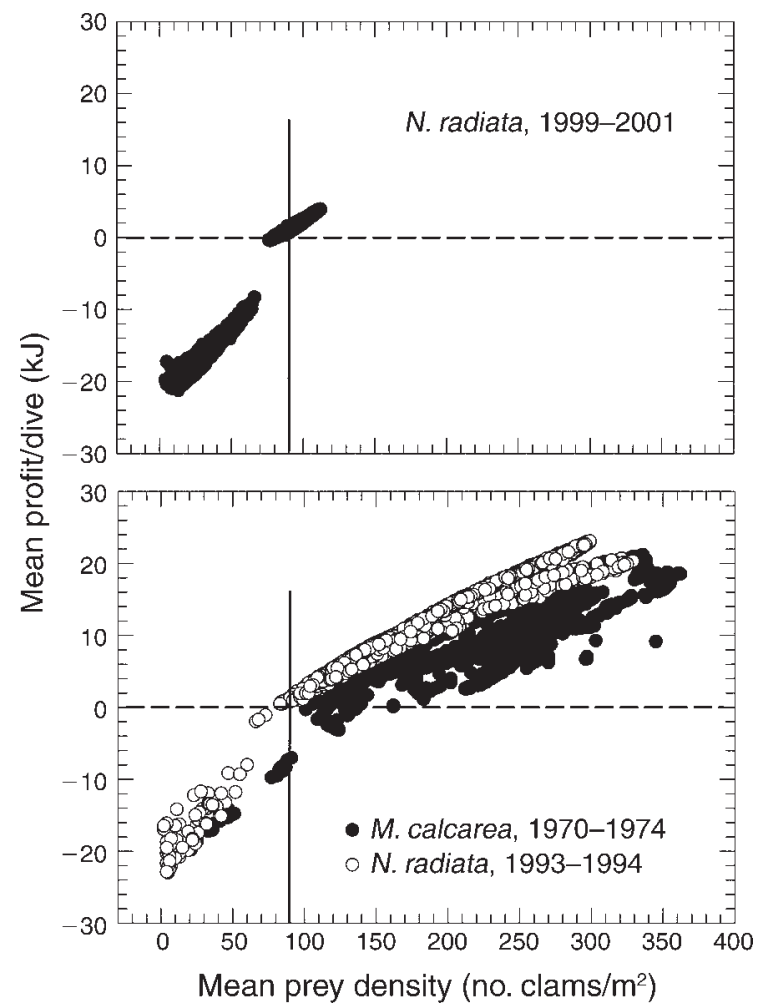

FIG. 8. Simulated mean profit per dive vs. mean density of the three clam length classes combined throughout winter for Spectacled Eiders foraging in the grids for M. calcarea in 1970 1974, N. radiata in 1993-1994, and N. radiata in 1999-2001 (Fig. 5). Profit per dive subsumes overhead costs during nonforaging periods throughout the diel period. Gaps in the plots reflect differing depths of similar prey concentrations. Viable habitat (positive mean profit per dive) generally occurred at densities $>90$ clams $/ \mathrm{m}^{2}$.

1994 and 1999 (Fig. 5), suggest that additional extreme changes might have occurred during the 20-year gap in sampling. Thus, the role of winter habitat conditions in the decline of Spectacled Eiders in western Alaska, and especially of the 1976-1977 regime shift from colder to warmer climate (Hare and Mantua 2000), remains unclear.

Having documented only one apparent cycle of major recruitment and decline of $N$. radiata in this area, it is also difficult for us to separate effects of directional climate change from those of regime shifts that may cycle at periods of several decades (e.g., Henriques et al. 2007). Climate change may in fact be manifested as changes in the frequency and duration of cyclic events, such as less frequent or less sustained recruitment. Consequently, for delineating critical habitat that will be adequate into the future, a more useful focus than assuming directional trend may be to identify processes related to periodic recruitment and decline of major prey, and long-term patterns of conditions that drive those processes (e.g., Möller 1986, Dekker and Beukema 2007). Such factors may include changes in organic 
matter supply due to altered extent or timing of sea ice and the ice-edge spring bloom (Lovvorn et al. 2005, Bluhm and Gradinger 2008), changes in ocean hydrography (Carroll et al. 2008), northward expansion of predators as water temperatures increase (Grebmeier et al. 2006), and altered patterns of spawning, larval dispersal, and postsettlement survival of prey (Palumbi and Hedgecock 2005). In particular, shifts in bivalve species and dispersion from almost complete absence to superabundance (Fig. 5) suggest the importance of refugia to recolonization. Thus, in addition to protecting localized areas that are currently used by eiders, it may be important to protect related habitats that provide recruits after large-scale disturbances or altered conditions (Lipcius et al. 2005). Better understanding of these processes should improve predictions and caveats for designating protected areas.

\section{Single-species models and design of marine protected areas}

Many approaches developed for delineating marine protected areas have focused on overall biodiversity (Neigel 2003). There is no law in the United States that safeguards biodiversity per se, but only the Endangered Species Act (ESA) which, by protecting critical habitat for a single species, may indirectly preserve entire ecosystems (e.g., old-growth forest habitats of Spotted Owls, Strix occidentalis). However, even strong provisions of the ESA appear inadequate to deal with shifting of habitats due to climate change, because critical habitat is usually delineated by fixed boundaries based on conditions when they were set (Ruhl 2008). These boundaries must be justified by thorough assessment of both ecological information and economic impacts, and the boundaries published in the U.S. Federal Register (for Spectacled Eiders, see Federal Register 66(25):91469185,6 February 2001). The relative inflexibility of this process would call for more liberal initial boundaries to account for changing conditions; however, more liberal boundaries that conflict with economic uses must be justified with scientific rigor adequate to resist legal challenge. In predicting an animal's ability to persist in broader areas under changing conditions, effects of complex interactions at scales from physiology to ecosystems often cannot be evaluated or even envisioned without integrative modeling tools (Turner et al. 1994, Stillman et al. 2005, Natori and Porter 2007). Mechanistic models that reveal what thresholds of what factors allow a species to persist, and the likely range of variation over time, can yield more reliable, quantitative projections of adequate habitat.

Effort required to develop such models is not trivial, but can be cost effective in the long term. In their habitat far offshore in the shifting pack ice, nomadic Spectacled Eiders are very difficult to access and observe, and cannot be captured and recaptured for applying conventional techniques such as time-depth recorders or doubly labeled water. A viable alternative is to integrate the best data available from captive birds or free-ranging analogous species into simulation models, which also yield predictive capability. Of sea ducks nesting in Alaska and northwest Canada, two eider species are listed as threatened under the ESA, two other eider species and two scoter species have declined by 40 $60 \%$, and Long-tailed Ducks (Bucephala clangula) have decreased by $75 \%$ (Hodges et al. 1996, Dickson and Gilchrist 2002). Similar trends for these and other sea duck species throughout North America and Europe (Kirby et al. 1993, Camphuysen et al. 2002, Merkel 2004) provide diverse applications for relevant models once developed. In addition to using such models to identify critical habitat now and into the future, thorough uncertainty analyses can help to avoid misallocating research funds to aspects that ultimately have little effect on habitat relations.

\section{Alternatives to fixed marine reserves}

All areas identified as viable habitat might not be required to support the Spectacled Eider population at a given time. However, without more comprehensive data, it is difficult to estimate the total standing stock of prey or total area needed to provide food for the eiders as well as their competitors (fish, crabs, gastropods, sea stars). Consequently, our conservative approach has focused on delineating all areas that contain the "primary constituent elements" required by Spectacled Eiders, rather than on estimating the minimum extent and quality of such areas needed to support a given number of birds. Eiders may expand their diet if current prey become less common relative to other taxa (Guillemette et al. 1992, Merkel et al. 2007). However, major declines in overall benthic biomass (Grebmeier et al. 2006) make diet diversification a less effective response to further reductions of current prey.

Given large variation in the habitat mosaic over time, and increasing effects of climate change, one might suggest that protecting adequate habitat for eiders in the long term requires closing their entire wintering region to bottom trawling. Such large-scale closures may be strongly challenged, perhaps reducing the closed area only to what can be justified under uncompromising scrutiny of scientific evidence (Ruhl 2008). Soft-bottom benthos are typically adapted to significant levels of disturbance, and rather severe natural disturbances by storms and by feeding gray whales and walruses may be important to maintaining biodiversity as well as the productivity and desirable size structure of prey (Klaus et al. 1990, Hall 1994). Moreover, major shifts in dominant prey taxa documented in this study occurred in the absence of bottom trawling, perhaps weakening arguments that disturbance by trawling would have greater or more detrimental effects than natural disturbances. Thus, an alternative to large-scale closures may be to gain better understanding of the frequencies, intensities, and scales of natural disturbance experienced by prey communities, to compare those findings to 
trawling disturbance at a range of scales (Thrush et al. 1998, Brown et al. 2005), and then to allocate trawling disturbance among areas in ways that avoid unacceptable impacts (Murawski et al. 2000). Linking process models with long-term data and field experiments will be key to considering natural variability in such plans (Jennings et al. 2005). Effects of trawling can be difficult to distinguish from climate-driven changes (JuradoMolina and Livingston 2002), but may be less prone to reversal if sustained in a given area.

\section{ACKNOWLEDGMENTS}

We thank the captains and crews of the U.S. Coast Guard Cutters Polar Sea and Polar Star, and the R/V Alpha Helix, for excellent logistical support. A. L. Balsom, J. H. W. Bartlett, J. L. Clement, C. C. De Ruyck, V. G. Egorov, H. P. Kelly, E. D. Mischke, E. E. Osnas, G. G. Sheffield, and K. Stevens provided dedicated shipboard and laboratory assistance. N. P. Nibbelink gave valuable help with GIS analyses, and R. C. Reeves provided excellent mentoring for J. R. Lovvorn in $\mathrm{C}++$ programming. J. B. Fadely and G. R. Balogh encouraged our work and arranged important financial support. This research was funded by the National Science Foundation, Office of Polar Programs grants OPP-9813979 to J. R. Lovvorn; ARC-0454454 to J. R. Lovvorn, J. M. Grebmeier, and L. W. Cooper; and OPP-9815241 and OPP-9910319 to J. M. Grebmeier and L. W. Cooper; a contract to J. R. Lovvorn from the Endangered Species program of the U.S. Fish and Wildlife Service in Anchorage, Alaska; North Pacific Research Board grant 820 to J. R. Lovvorn (this is NPRB Publication \#125); and a Sabbatical Fellowship to J. R. Lovvorn from the National Center for Ecological Analysis and Synthesis, a center funded by the National Science Foundation (DEB-0553768), the University of California-Santa Barbara, and the State of California.

\section{Literature Cited}

Allison, G. W., S. D. Gaines, J. Lubchenko, and H. P. Possingham. 2003. Ensuring persistence of marine reserves: catastrophes require adopting an insurance factor. Ecological Applications 13(Supplement):S8-S24.

Amano, T., K. Ushiyama, S. Moriguchi, G. Fujita, and H. Higuchi. 2006. Decision-making in group foragers with incomplete information: test of individual-based model in geese. Ecological Monographs 76:601-616.

Araújo, M. B., M. Cabezas, W. Thuiller, L. Hannah, and P. H. Williams. 2004. Would climate change drive species out of reserves? An assessment of existing reserve-selection methods. Global Change Biology 10:1618-1626.

Barnes, P. W., and J. P. Thomas, editors. 2005. Benthic habitats and the effects of fishing. American Fisheries Society Symposium 41.

Baudinette, R. V., and P. Gill. 1985. The energetics of 'flying' and 'paddling' in water: locomotion in penguins and ducks. Journal of Comparative Physiology B 155:373-380.

Beauchamp, G., M. Bélisle, and L.-A. Giraldeau. 1997. Influence of conspecific attraction on the spatial distribution of learning foragers in a patchy habitat. Journal of Animal Ecology 66:671-682.

Bernstein, C., A. Kacelnik, and J. R. Krebs. 1988. Individual decisions and the distribution of predators in a patchy environment. Journal of Animal Ecology 57:1007-1026.

Bluhm, B. A., and R. Gradinger. 2008. Regional variability in food availability for Arctic marine mammals. Ecological Applications 18(Supplement):S77-S96.

Boersma, P. D., D. L. Stokes, and I. J. Strange. 2002. Applying ecology to conservation: tracking penguins at New Island
South reserve, Falkland Islands. Aquatic Conservation: Marine and Freshwater Ecosystems 12:63-74.

Brothers, N. P. 1985. Breeding biology, diet and morphometrics of the King Shag, Phalacrocorax albiventer purpurascens, at Macquarie Island. Australian Wildlife Research 12:81-94.

Brown, E. J., B. Finney, S. Hills, and M. Dommisse. 2005. Effects of commercial otter trawling on benthic communities in the southeastern Bering Sea. American Fisheries Society Symposium 41:439-460.

Bump, J. K., and J. R. Lovvorn. 2004. Effects of lead structure in Bering Sea pack ice on the flight costs of wintering Spectacled Eiders. Journal of Marine Systems 50:113-139.

Camphuysen, C. J., C. M. Berrevoets, H. J. W. M. Cremers, A. Dekinga, R. Dekker, B. J. Ens, T. M. van der Have, R. K. H. Kats, T. Kuiken, M. F. Leopold, J. van der Meer, and T. Piersma. 2002. Mass mortality of Common Eiders (Somateria mollissima) in the Dutch Wadden Sea, winter 1999/2000: starvation in a commercially exploited wetland of international importance. Biological Conservation 106:303-317.

Carroll, M. L., S. G. Denisenko, P. E. Renaud, and W. G. Ambrose. 2008. Benthic infauna of the seasonally ice-covered western Barents Sea: patterns and relationships to environmental forcing. Deep-Sea Research II 55:2340-2351.

Clement, J. L., L. W. Cooper, and J. M. Grebmeier. 2004. Late winter water column and sea ice conditions in the northern Bering Sea. Journal of Geophysical Research 109:C03022.

Conners, M. E., A. B. Hollowed, and E. Brown. 2002. Retrospective analysis of Bering Sea bottom trawl surveys: regime shift and ecosystem reorganization. Progress in Oceanography 55:209-222.

Cooper, L. W., C. J. Ashjian, S. L. Smith, L. A. Codispoti, J. M. Grebmeier, R. G. Campbell, and E. B. Sherr. 2006. Rapid seasonal sea-ice retreat in the Arctic could be affecting Pacific walrus (Odobenus rosmarus divergens) recruitment. Aquatic Mammals 32:98-102.

Croll, D. A., A. J. Gaston, A. E. Burger, and D. Konnoff. 1992. Foraging behavior and physiological adaptation for diving in Thick-billed Murres. Ecology 73:344-356.

Day, R. H., J. R. Rose, A. K. Pritchard, R. J. Blaha, and B. A. Cooper. 2004. Environmental effects on the fall migration of eiders at Barrow, Alaska. Marine Ornithology 32:13-24.

Dekker, R., and J. J. Beukema. 2007. Long-term and large-scale variability in productivity of the tellinid bivalve Macoma balthica on Wadden Sea tidal flats. Marine Ecology Progress Series 337:117-134.

Dickson, D. L., and H. G. Gilchrist. 2002. Status of marine birds of the southeastern Beaufort Sea. Arctic 55:46-58.

ESRI. 2001. Using ArcGIS Geostatistical Analyst. ESRI, Redlands, California, USA.

Flint, P. L., J. B. Grand, J. A. Morse, and T. F. Fondell. 2000. Late summer survival of adult female and juvenile Spectacled Eiders on the Yukon-Kuskokwim Delta, Alaska. Waterbirds 23:292-297.

Fuller, T., D. P. Morton, and S. Sarkar. 2008. Incorporating uncertainty about species' potential distributions under climate change into the selection of conservation areas with a case study from the Arctic Coastal Plain of Alaska. Biological Conservation 141:1547-1559.

Gilbert, C., G. Robertson, Y. Le Maho, Y. Naito, and A. Ancel. 2006. Huddling behavior in Emperor Penguins: dynamics of huddling. Physiology and Behavior 88:479-488. Grand, J. B., P. L. Flint, M. R. Petersen, and C. L. Moran. 1998. Effect of lead poisoning on Spectacled Eider survival rates. Journal of Wildlife Management 62:1103-1109.

Grebmeier, J. M., and L. W. Cooper. 1995. Influence of the St. Lawrence Island polynya upon the Bering Sea benthos. Journal of Geophysical Research 100:4439-4460.

Grebmeier, J. M., J. E. Overland, S. E. Moore, E. V. Farley, E. C. Carmack, L. W. Cooper, K. E. Frey, J. H. Helle, F. A. McLaughlin, and S. L. McNutt. 2006. A major ecosystem shift in the northern Bering Sea. Science 311:1461-1464. 
Guillemette, M. 1994. Digestive-rate constraint in wintering Common Eiders (Somateria mollissima): implications for flying capabilities. Auk 111:900-909.

Guillemette, M., R. C. Ydenberg, and J. H. Himmelman. 1992. The role of energy intake rate in prey and habitat selection of Common Eiders Somateria mollissima in winter: a risksensitive interpretation. Journal of Animal Ecology 61:599610.

Hall, S. J. 1994. Physical disturbance and marine benthic communities: life in unconsolidated sediments. Oceanography and Marine Biology: An Annual Review 32:179-239.

Hannah, L., G. Midgley, S. Andelman, M. Araújo, G. Hughes, E. Martinez-Meyer, R. Pearson, and P. Williams. 2007. Protected area needs in a changing climate. Frontiers in Ecology and the Environment 5:131-138.

Hare, S. R., and N. J. Mantua. 2000. Empirical evidence for North Pacific regime shifts in 1977 and 1989. Progress in Oceanography 47:103-145.

Hawkins, P. A. J., P. J. Butler, A. J. Woakes, and J. R. Speakman. 2000. Estimation of the rate of oxygen consumption of the Common Eider duck (Somateria mollissima), with some measurements of heart rate during voluntary dives. Journal of Experimental Biology 203:2819-2832.

Heath, J. P., H. G. Gilchrist, and R. C. Ydenberg. 2006. Regulation of stroke pattern and swim speed across a range of current velocities: diving by Common Eiders wintering in the Canadian Arctic. Journal of Experimental Biology 209: 3974-3983.

Henriques, M., E. J. Gonçalves, and V. C. Almada. 2007. Rapid shifts in a marine fish assemblage follow fluctuations in winter sea conditions. Marine Ecology Progress Series 340: 259-270.

Hodges, J. I., J. G. King, B. Conant, and H. A. Hanson. 1996. Aerial surveys of waterbirds in Alaska 1957-94: population trends and observer variability. National Biological Service Information and Technology Report 4. U.S. Department of the Interior, Washington, D.C., USA.

Hooker, S. K., H. Whitehead, and S. Gowans. 1999. Marine protected area design and the spatial and temporal distribution of cetaceans in a submarine canyon. Conservation Biology 13:592-602.

Humphreys, E. M., S. Wanless, and D. M. Bryant. 2007. Elevated metabolic costs while resting on water in a surface feeder: the Black-legged Kittiwake Rissa tridactyla. Ibis 149: $106-111$.

Jennings, S., S. Freeman, R. Parker, D. E. Duplisea, and T. A. Dinmore. 2005. Ecosystem consequences of bottom fishing disturbance. American Fisheries Society Symposium 41:7390.

Jenssen, B., M. Ekker, and C. Bech. 1989. Thermoregulation in winter-acclimatized Common Eiders (Somateria mollissima) in air and water. Canadian Journal of Zoology 67:669-673.

Jurado-Molina, J., and P. Livingston. 2002. Climate-forcing effects on trophically linked groundfish populations: implications for fisheries management. Canadian Journal of Fisheries and Aquatic Sciences 59:1941-1951.

Kaseloo, P. A., and J. R. Lovvorn. 2003. Heat increment of feeding and thermal substitution in Mallard ducks feeding voluntarily on grain. Journal of Comparative Physiology B 173:207-213.

Kaseloo, P. A., and J. R. Lovvorn. 2005. Effects of surface activity patterns and dive depth on thermal substitution in fasted and fed Lesser Scaup ducks (Aythya affinis). Canadian Journal of Zoology 83:301-311.

Kato, A., J. P. Croxall, Y. Watanuki, and Y. Naito. 1992. Diving patterns and performance in male and female Blueeyed Cormorants Phalacrocorax atriceps at South Georgia. Marine Ornithology 19:117-129.

Kirby, J. S., R. J. Evans, and A. D. Fox. 1993. Wintering seaducks in Britain and Ireland: populations, threats, conservation and research priorities. Aquatic Conservation: Marine and Freshwater Ecosystems 3:105-137.

Klaus, A. D., J. S. Oliver, and R. G. Kvitek. 1990. The effects of gray whale, walrus, and ice gouging disturbance on benthic communities in the Bering Sea and Chukchi Sea, Alaska. National Geographic Research 6:470-484.

Kröncke, I., J. W. Dippner, H. Heyen, and B. Zeiss. 1998. Long-term changes in macrofaunal communities off Norderney (East Frisia, Germany) in relation to climate variability. Marine Ecology Progress Series 167:25-36.

Kruse, G. H. 2007. Written testimony for Hearing on the Effects of Climate Change and Ocean Acidification on Living Marine Resources. Subcommittee on Oceans, Atmosphere, Fisheries, and Coast Guard, United States Senate, 10 May 2007. 〈http:// commerce.senate.gov/public/index.cfm?FuseAction=Hearings. Testimony\&Hearing_ID=29e2541e-88e1-44fc-be93-679744bac4ba\& Witness_ID=c9ac7d38-0009-40e8-8a55-0833412a1b28>

Lewis, T. L., D. Esler, W. S. Boyd, and R. Žydelis. 2005. Nocturnal foraging behavior of wintering Surf Scoters and White-winged Scoters. Condor 107:637-647.

Lipcius, R. N., L. B. Crowder, and L. E. Morgan. 2005. Metapopulation structure and marine reserves. Pages 328345 in E. A. Norse and L. B. Crowder, editors. Marine conservation biology. Island Press, Washington, D.C., USA.

Louzao, M., K. D. Hyrenbach, J. M. Arcos, P. Abelló, L. G. De Sola, and D. Oro. 2006. Oceanographic habitat of an endangered Mediterranean Procellariiform: implications for marine protected areas. Ecological Applications 16:16831695.

Lovvorn, J. R. 1987. Behavior, energetics, and habitat relations of Canvasback ducks during winter and early spring migration. Dissertation. University of Wisconsin, Madison, Wisconsin, USA.

Lovvorn, J. R. 2007. Thermal substitution and aerobic efficiency: measuring and predicting effects of heat balance on endotherm diving energetics. Philosophical Transactions of the Royal Society of London B 362:2079-2093.

Lovvorn, J. R., L. W. Cooper, M. L. Brooks, C. C. De Ruyck, J. K. Bump, and J. M. Grebmeier. 2005. Organic matter pathways to zooplankton and benthos under pack ice in late winter and open water in late summer in the north-central Bering Sea. Marine Ecology Progress Series 291:135-150.

Lovvorn, J. R., and M. P. Gillingham. 1996. Food dispersion and foraging energetics: a mechanistic synthesis for field studies of avian benthivores. Ecology 77:435-451.

Lovvorn, J. R., D. R. Jones, and R. W. Blake. 1991. Mechanics of underwater locomotion in diving ducks: drag, buoyancy and acceleration in a size gradient of species. Journal of Experimental Biology 159:89-108.

Lovvorn, J. R., S. E. Richman, J. M. Grebmeier, and L. W. Cooper. 2003. Diet and body condition of Spectacled Eiders wintering in pack ice of the Bering Sea. Polar Biology 26:259267.

Lovvorn, J. R., Y. Watanuki, A. Kato, Y. Naito, and G. A. Liggins. 2004. Stroke patterns and regulation of swim speed and energy cost in free-ranging Brünnich's Guillemots. Journal of Experimental Biology 207:4679-4695.

Mautino, M., and J. U. Bell. 1986. Experimental lead toxicity in the Ring-necked Duck. Environmental Research 41:538-545.

Mautino, M., and J. U. Bell. 1987. Hematological evaluation of lead intoxication in Mallards. Bulletin of Environmental Contamination and Toxicology 38:78-85.

McConnaughey, R. A., K. L. Mier, and C. B. Dew. 2000. An examination of chronic trawling effects on soft-bottom benthos of the eastern Bering Sea. ICES Journal of Marine Science 57:1377-1388.

McMahon, C. R., and G. C. Hays. 2006. Thermal niche, largescale movements and implications of climate change for a critically endangered marine vertebrate. Global Change Biology 12:1330-1338. 
Merkel, F. R. 2004. Evidence of population decline in Common Eiders breeding in western Greenland. Arctic 57:27-36.

Merkel, F. R., A. Mosbech, S. E. Jamieson, and K. Falk. 2007. The diet of King Eiders wintering in Nuuk, southwest Greenland, with reference to sympatric wintering Common Eiders. Polar Biology 30:1593-1597.

Möller, P. 1986. Physical factors and biological interactions regulating infauna in shallow boreal areas. Marine Ecology Progress Series 30:33-47.

Murawski, S. A., R. Brown, H.-L. Lai, P. J. Rago, and L. Hendrickson. 2000. Large-scale closed areas as a fisherymanagement tool in temperate marine systems: the Georges Bank experience. Bulletin of Marine Science 66:775-798.

Murphy, D. D., and B. R. Noon. 1992. Integrating scientific methods with habitat conservation planning: reserve design for Northern Spotted Owls. Ecological Applications 2:3-17.

Natori, Y., and W. P. Porter. 2007. Model of Japanese serow (Capricornis crispus) energetics predicts distribution on Honshu, Japan. Ecological Applications 17:1441-1459.

Neigel, J. E. 2003. Species-area relationships and marine conservation. Ecological Applications 13(Supplement): S138-S145.

Niebauer, H. J., N. A. Bond, L. P. Yakunin, and V. V. Plotnikov. 1999. An update on the climatology and sea ice of the Bering Sea. Pages 29-59 in T. R. Loughlin and K. Ohtani, editors. Dynamics of the Bering Sea. University of Alaska Sea Grant, Fairbanks, Alaska, USA.

Overland, J. E., and M. Wang. 2007. Future regional sea ice declines. Geophysical Research Letters 34:L17705.

Palumbi, S. R., and D. Hedgecock. 2005. The life of the sea: implications of marine population biology to conservation policy. Pages 33-46 in E. A. Norse and L. B. Crowder, editors. Marine conservation biology. Island Press, Washington, D.C., USA.

Pautzke, C. 2005. The challenge of protecting fish habitat through the Magnuson-Stevens Fishery Conservation and Management Act. American Fisheries Society Symposium 42:19-39.

Pearson, R. G., and T. P. Dawson. 2003. Predicting the impacts of climate change on the distribution of species: are bioclimate envelope models useful? Global Ecology and Biogeography 12:361-371.

Pease, C. H. 1980. Eastern Bering Sea ice processes. Monthly Weather Review 108:2015-2023.

Pennycuick, C. J. 1989. Bird flight performance: a practical calculation manual. Oxford University Press, Oxford, UK.

Perry, A. L., P. J. Low, J. R. Ellis, and J. D. Reynolds. 2005. Climate change and distribution shifts in marine fishes. Science 308:1912-1915.

Petersen, M. R., and D. C. Douglas. 2004. Winter ecology of Spectacled Eiders: environmental characteristics and population change. Condor 106:79-94.

Petersen, M. R., J. B. Grand, and C. P. Dau. 2000. Spectacled Eider (Somateria fischeri). The Birds of North America 537. The Birds of North America, Philadelphia, Pennsylvania, USA.

Petersen, M. R., W. W. Larned, and D. C. Douglas. 1999. Atsea distribution of Spectacled Eiders: a 120-year-old mystery resolved. Auk 116:1009-1020.

Prange, H. D., and K. Schmidt-Nielsen. 1970. The metabolic cost of swimming in ducks. Journal of Experimental Biology 53:763-777.

Rhodes, J. R., J. G. Callaghan, C. A. McAlpine, C. de Jong, M. E. Bowen, D. L. Mitchell, D. Lunney, and H. P.
Possingham. 2008. Regional variation in habitat-occupancy thresholds: a warning for conservation planning. Journal of Applied Ecology 45:549-557.

Richman, S. E., and J. R. Lovvorn. 2003. Effects of clam species dominance on nutrient and energy acquisition by Spectacled Eiders in the Bering Sea. Marine Ecology Progress Series 261:283-297.

Richman, S. E., and J. R. Lovvorn. 2008. Costs of diving by wing and foot propulsion in a sea duck, the White-winged Scoter. Journal of Comparative Physiology B 178:321-332.

Ruhl, J. B. 2008. Climate change and the Endangered Species Act: building bridges to the no-analog future. Boston University Law Review 88:1-62.

Scheffer, M., S. Carpenter, J. A. Foley, C. Folkes, and B. Walker. 2001. Catastrophic shifts in ecosystems. Nature 413: 591-596.

Southall, E. J., D. W. Sims, M. J. Witt, and J. D. Metcalfe. 2006. Seasonal space-use estimates of basking sharks in relation to protection and political-economic zones in the north-east Atlantic. Biological Conservation 132:33-39.

Stillman, R. A., A. D. West, J. D. Goss-Custard, S. McGrorty, N. J. Frost, D. J. Morrisey, A. J. Kenny, and A. L. Drewitt. 2005. Predicting site quality for shorebird communities: a case study on the Humber estuary, UK. Marine Ecology Progress Series 305:203-217.

Stirling, I., and C. L. Parkinson. 2006. Possible effects of climate warming on selected populations of polar bears (Ursus maritimus) in the Canadian Arctic. Arctic 59:261-275.

Stoker, S. W. 1978. Benthic invertebrate macrofauna of the eastern continental shelf of the Bering and Chukchi Seas. Dissertation. University of Alaska, Fairbanks, Alaska, USA.

Systad, G. H., J. O. Bustnes, and K. E. Erikstad. 2000. Behavioral responses to decreasing day length in wintering sea ducks. Auk 117:33-40.

Thrush, S. F., J. E. Hewitt, V. J. Cummings, P. K. Dayton, M. Cryer, S. J. Turner, G. A. Funnell, R. G. Budd, C. J. Milburn, and M. R. Wilkinson. 1998. Disturbance of the marine benthic habitat by commercial fishing: impacts at the scale of the fishery. Ecological Applications 8:866-879.

Turner, M. G., Y. Wu, L. L. Wallace, W. H. Romme, and A. Brenkert. 1994. Simulating winter interactions among ungulates, vegetation, and fire in northern Yellowstone Park. Ecological Applications 4:472-496.

U.S. Fish and Wildlife Service. 1996. Spectacled Eider Recovery Plan. Anchorage, Alaska, USA.

Wilson, R. P., and F. Quintana. 2004. Surface pauses in relation to dive duration in Imperial Cormorants; how much time for a breather? Journal of Experimental Biology 207:1789-1796. Witt, M. J., A. C. Broderick, D. J. Johns, C. Martin, R. Penrose, M. S. Hoogmoed, and B. J. Godley. 2007. Prey landscapes help identify potential foraging habitats for leatherback turtles in the NE Atlantic. Marine Ecology Progress Series 337:231-244.

Wyllie-Echeverria, T., and W. S. Wooster. 1998. Year-to-year variations in Bering Sea ice cover and some consequences for fish distributions. Fisheries Oceanography 7:159-170.

Zheng, J., G. H. Kruse, and D. R. Ackley. 2001. Spatial distribution and recruitment patterns of snow crabs in the eastern Bering Sea. Pages 233-255 in G. H. Kruse, N. Bez, A. Booth, M. W. Dorn, S. Hills, R. N. Lipcius, D. Pelletier, C. Roy, S. J. Smith, and D. Witherell, editors. Spatial processes and management of marine populations. Alaska Sea Grant, AK-SG-01-02, Fairbanks, Alaska, USA.

\section{APPENDIX}

Detailed explanations of model parameters and algorithms (Ecological Archives A019-064-A1). 